\title{
Research on Designing an Industrial Product-Service System with Uncertain Customer Demands
}

\author{
Fei Zhang ${ }^{(D}$, Liecheng Jia, and Weizhen Han \\ Institute of Mechanical Engineering, \\ Key Laboratory of Intelligent Manufacturing Quality Big Data Tracing and Analysis of Zhejiang Province, \\ China Jiliang University, Hangzhou 310018, China \\ Correspondence should be addressed to Fei Zhang; zhfei@cjlu.edu.cn
}

Received 6 August 2020; Revised 22 February 2021; Accepted 1 March 2021; Published 20 March 2021

Academic Editor: Yi Su

Copyright (c) 2021 Fei Zhang et al. This is an open access article distributed under the Creative Commons Attribution License, which permits unrestricted use, distribution, and reproduction in any medium, provided the original work is properly cited.

\begin{abstract}
The industrial product-service system (iPSS) is a kind of system engineering methodology, integration scheme, and business model to realize service value by adding intangible services in the whole life cycle. However, the design of the system involves many difficulties such as uncertain customer demands, strong subjectivity of the experience design, and long debugging times. Methods for solving upper problems are therefore essential. This paper presents a design model that integrates an improved affinity propagation (AP) clustering algorithm, quality function development (QFD), and axiomatic design (AD). The entire process of designing an iPSS can be split into three steps. First, uncertain customer demands is determined and standardized. Second, the functions of the product-service system are investigated. Finally, the structures of the system are determined. This paper examines the example of the control service of an iPSS for a water heater tank capping press. An improved AP clustering algorithm is used to determine standardized customer demands, the proposed QFD, and an AD integration model to initially establish a mapping between the customer demands domain and the function domain and clarify the design focus. Next, a QFDand AD-integrated model is constructed to establish a mapping between the function domain and the structure domain and optimize the control scheme through the quality of its risk prediction. Finally the paper verifies that the upper process and methods can guide the design process effectively in production applications.
\end{abstract}

\section{Introduction}

The Made in China 2025 policy lists intelligent manufacturing as one of China's five key projects and presents a comprehensive plan to develop the intelligent manufacturing industry [1]. In 2006, the Weishang factory cooperated with Yuanfang Software Company to carry out the first furniture informatization renovation in China, and in 2016, it was awarded as the only smart manufacturing demonstration base in the home furnishing industry [2]. At the same time, Sinopec Jiujiang Branch integrated modern information technology and established a digital monitoring and optimization system, covering the entire process of "management, production, operation, and warehousing," becoming a sample of intelligent transformation of processoriented manufacturing [3]. Zhejiang Toman Machinery
Co., Ltd. introduced intelligent manufacturing technology in 2013 to improve product quality and production efficiency. Since 2014, Toman has used self-developed systems to provide SMEs (small and medium-sized enterprises) with customized solutions, such as TM-e (a production management system) and TM-SPC (a quality control system). Toman has transformed from an equipment manufacturer to a production system integrator [4]. With the continuous development of intelligent manufacturing in practice, a variety of different themes have emerged. These themes include the Internet of things [5], big data manufacturing [6], cloud manufacturing [7], and digital twin [8], which play a positive role in guiding the technological upgrading of the manufacturing industry. For example, Jiang et al. [9-11] developed a new MATLAB toolbox, the data-based key performance indicator-oriented fault detection toolbox 
(DB-KIT), for evaluating the influence of the detected faults on systems behavior, reviewed the key scientific issues in the design and implementation of soft sensors in modern industry, and also proposed a research route centered on the construction of performance evaluation system and performance-oriented fault diagnosis methods. Su and $\mathrm{Yu}$ [12] constructed a spatial econometric model with geographical proximity as the spatial weight to study the effect of spatial agglomeration of new energy industries on regional pollution control performance. The development of the intelligent manufacturing industry has driven the rapid development of the industrial product-service system (iPSS) in China. Zhu et al. [13] comprehensively considered processing time, cost, and quality and proposed a machining capability model for quantifying and measuring machining capabilities of an mtiPSS (industrial product-service system of a machine tool). Based on the tool-based industrial product-service system, Sun et al. [14] further studied the tool delivery method in the iPSS, established a cutting tool demand prediction model and a tool delivery model, and proposed a novel cutting tool service model. Ding et al. [15] discussed the multiobjective resource scheduling problem in the operation phase of iPSS, used an improved NSGA-II algorithm to solve the multiobjective problem including comprehensive customer satisfaction degree, resource utilization efficiency, and productservice cost, and verified the feasibility with a case of China Yufeng Electric Power Company. Leng et al. [16] proposed the concept of a cost-effective industrial product-service system for oil sands mining (om-iPSS). Haeberle et al. [17] proposed a method of systematically establishing service parameters to enhance the effectiveness of industrial service systems for establishing new services. However, there is no analysis and research on how the service parameters can be obtained from customer needs. Industrial electronic control systems constitute the control core of the iPSS of complete equipment. Usually, the control system's design is based on customer demands. The designer creates a control system's software and hardware design based on personal experience and professional knowledge. However, this design method is inadequate. First, customers are restricted by the professional's knowledge and resource conditions, customers' demands are often unclear and hard to determine, and the method involves too many ambiguities and uncertainties. Second, designers have different levels of experience and lack scientific theory to guide the design process. Therefore, when customer demands are uncertain, it is difficult for the designer to deliver a good product/service. It is, therefore, critical that the iPSS of complete equipment be provided with accurate information about customer demands to quickly design a satisfactory control system.

Quality function deployment (QFD) and axiomatic design (AD) are product design methods driven by customer demand that have been widely used in other product design fields. For example, Chang et al. [18] applied QFD theory to electric vehicles and provided an effective and scientific development tool for electric vehicle manufacturers. Wang et al. [19] used QFD theory to solve a multiobjective decision problem in a collaborative supply chain network. Han et al. [20] applied QFD theory to the field of augmented reality design, achieving collaborative customer innovation and improving customer satisfaction. Avikal et al. [21] constructed a new method based on the fuzzy Kano model and QFD theory for designing the exterior of a sport utility vehicle. The project QFD tool developed by Chao et al. [22] was used by an electronics company in Japan to engage in semiconductor projects and business model development to help deploy solution elements and resources. Vinodh et al. [23] considered environmental factors at various stages of QFD and proposed the QFDE method, which was applied to the Indian rotary switch manufacturing organization to achieve an environmentally conscious design in the early stages of product development. The SOFRAGRAF Company used QFD for the design of hand tools, staplers, nailing machines, etc. [24] In addition, QFD was used to design university textbooks and improve the quality of courses. Rainstar University in Scottsdale, Arizona, applied QFD to the redesign of higher education courses. [25] Liu et al. [26] established a conceptual design process model by applying the theory of inventive problem solving and $\mathrm{AD}$ to the innovative design of the manipulator. Tamayo et al. [27] combined $\mathrm{AD}$ and a design structure matrix to determine customer demands at the conceptual design stage of a manufacturing system. Goo et al. [28] introduced independence and failure modes in $\mathrm{AD}$ to improve the reliability of the product design process. Pétursson et al. [29] used AD to complete the research and development of shape-memory alloy spring static test equipment. Bae et al. [30] used independent axioms to define the relationship between hard points and suspension geometries and improve suspension system design and proposed a sequential kinematics design of suspension system based on the axiomatic design (AD). Lo and Helander [31] developed a method based on AD to identify couplings and make recommendations to eliminate couplings. This method was applied to the design of adjustable microscope workstations and the design of manual SLR (single-lens-reflex) cameras. Durmusoglu and Kulak [32] developed a method of designing efficient office operations using AD principles, which improves office operations and enhances business competitiveness by reducing customer delivery times. Ferrer et al. [33] proposed a twostage method based on the $\mathrm{AD}$ method to define the structure of manufacturing knowledge and develop a knowledge-based DFM (Design for Manufacturing) application for connecting rod and internal combustion engine parts' design.

Given this background, QFD can clearly define the design focus of a product-service system, and the importance of customer demands can be transmitted by the house of quality (HoQ). However, QFD is based on an empirical design and lacks objective criteria; therefore, it is impossible to verify the rationality of the design process [34]. AD provides a set of scientific design methods and axioms that can verify this rationality, but there are no effective means to map between the customer demand domain and the function domain, and the design's emphasis cannot be clearly defined. This paper, therefore, introduces a new method integrated with $\mathrm{AP}, \mathrm{QFD}$, and $\mathrm{AD}$ to design a control system for the iPSS of complete equipment. 
As shown in Figure 1, the design model starts with an analysis of customer demands. It then uses an improved AP clustering algorithm to complete the cluster analysis of the original customer demands information. Next, it establishes a system for the functional HoQ to complete the mapping between the demand domain and the function domain. Finally, following $\mathrm{AD}$ theory, the function domain is mapped to the structure domain. Moreover, based on this, risk prediction of the HoQ is established to optimize the system structure. The proposed QFD and an AD integration model initially establish a mapping between the customer demand domain and the function domain and clarify the design focus.

Moreover, in view of the vagueness, dispersion, and uncertainty of customer demands obtained from interviews and questionnaires, this paper proposes an AP clustering algorithm based on a weighted network. The algorithm uses an intuitionistic fuzzy decision matrix to quantify the correlation between demand nodes, uses a weighted network to determine the distribution density of demand nodes, and then determines the selection of initial deviation parameters $P$.

This paper will take the control service design of an iPSS for a water heater tank capping press as example. The improved AP clustering algorithm will be used to determine standardized customer demands. Then the QFD and an AD integration model will be used to initially establish a mapping between the customer demand domain and the function domain and clarify the design focus. Finally, a QFD- and AD-integrated model will be constructed to establish a mapping between the function domain and the structure domain and optimize the control scheme through the quality of its risk prediction.

\section{Cluster Analysis of Customer Demands}

QFD and $\mathrm{AD}$ are driven by customer demands; thus, the accuracy of these demands is very important. Fuzzy or uncertain customer demands will affect the rationality and accuracy of the subsequent design process. However, due to limitations in professional knowledge, resource conditions, and so on, customers' requirement descriptions have certain ambiguities and uncertainties. Therefore, to standardize customer demands, this paper proposes an AP clustering algorithm based on a weighted network for a cluster analysis of customer demands.

\subsection{AP Clustering Algorithm Based on a Weighted Network.} The basic idea of an AP clustering algorithm is to use all the data points as potential clustering centers and perform clustering on a similarity matrix of the data points [35]. The AP clustering algorithm has yielded good results in applications such as image processing, community detection, and fault diagnosis because of its strong clustering stability and lack of predefined information [36, 37]. Zhang proposed an improved $K$-means algorithm and an improved AP clustering algorithm to determine the modular configuration of service elements [38, 39]. However, research on the AP clustering algorithm in the processing of customer demand information is still lacking.

In the AP clustering algorithm, responsibility $r(i, k)$ and availability $a(i, k)$ represent two types of data object information [40]. As shown in Figure 2, $r(i, k)$ describes the suitability of data object $k$ as the clustering center of data object $i$. It also represents the message from $i$ to $k$. The term $A$ $(i, k)$ describes the suitability of data object $i$ as the clustering center of data object $k$. It also represents the message from $k$ to $i$. At the end of the affinity propagation, the class representative point $x_{i}$ is determined to be $x_{k}$, where $k$ satisfies

$$
\arg _{k} \min (a(i, k)+r(i, k)) \text {. }
$$

The iterative process of the AP algorithm involves alternating the updates of two information sources. As shown in the following equation, when the sum of the $r(i, k)$ and $a$ $(i, k)$ values of all the data points for any $x_{i}$ is calculated, the representative point of the class of $x_{i}$ is $x_{k}$ :

$$
r(i, k)+a(i, k)=s(i, k)+a(i, k)-\max _{k^{\prime} \neq k}\left[a\left(i, k^{\prime}\right)+s\left(i, k^{\prime}\right)\right] .
$$

The AP algorithm refers to the message transmission of data points. Normally, a sample's representativeness can be determined by its reliability and validity. If the change value of $a(i, k)$ and $r(i, k)$ is the highest, then $k_{x}$ is a representative sample of $i_{x}$. When the local $a(i, k)$ and $r(i, k)$ values no longer change, messaging will stop [41].

Additionally, the AP clustering algorithm introduces a damping factor $\lambda$ and a deviation parameter $P$. The factor $\lambda$ has a value range $[0,1]$ and is used to adjust the convergence rate of the algorithm and the stability of the iterative process. Generally, $\lambda=0.5$ is selected. When the iterative process has large oscillations, the value of $\lambda$ can be accordingly reduced or increased. The parameter $P$ has a value range $[0,1]$, which is the criterion for a data point $i$ becoming a cluster center. The larger the value, the greater the probability of the point becoming a cluster center, and vice versa. When $P$ is less than or greater than a certain threshold, the number of clusters will change [42]. Therefore, the AP clustering algorithm has certain limitations in terms of the initial bias [43].

The steps of the AP clustering algorithm are as follows $[44,45]$.

Step 1: use the Euclidean distance between data points $i$ and $j$ to calculate the similarity $s(i, j)$ :

$$
s(i, j)=-x_{i}-x_{j}^{2}, \quad i \neq j .
$$

Step 2: assign an initial preference to each data point in the sample, where the value range of $P$ is $[0,1]$.

Step 3: calculate $r(i, k)$, such that

$$
r(i, k) \leftarrow s(i, k)-\max _{j \neq k}[s(i, j)+a(i, j)] .
$$




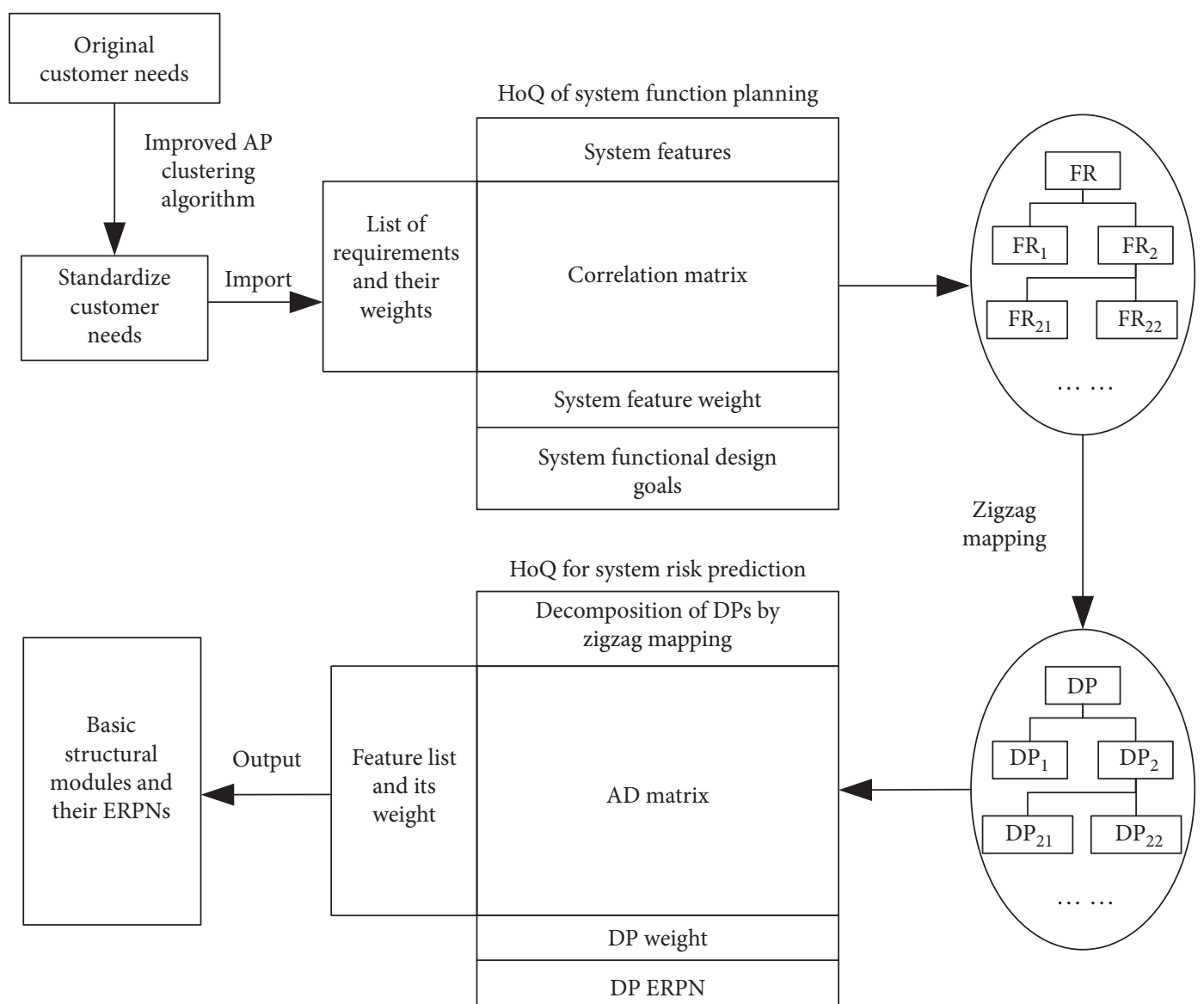

FIGURE 1: Design model integrating AP/QFD/AD, with functional requirements (FR), design parameters (DPs), and extended risk priority numbers (ERPNs).
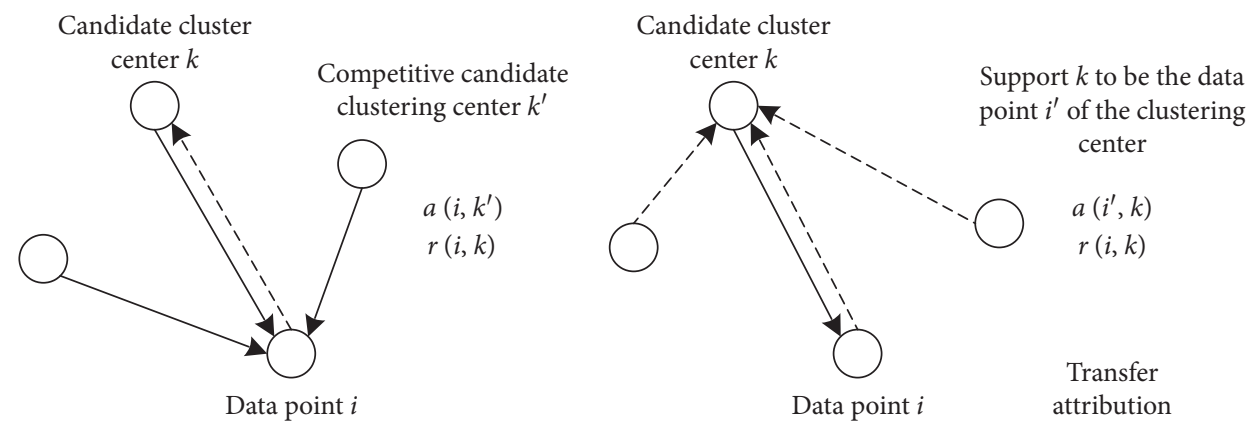

FIGURE 2: AP clustering algorithm message transmission.

Step 4: calculate $a(i, k)$, such that

$$
\begin{gathered}
a(i, k) \leftarrow \min \left\{0, r(k, k)+\sum_{j \neq i, k} \max [0, r(j, k)]\right\}, \\
a(k, k) \leftarrow \sum_{j \neq k} \max [0, r(j, k)] .
\end{gathered}
$$

Step 5: update $r(i, k)$ and $a(i, k)$, respectively, according to

$$
r_{i+1}(i, k)=\lambda \cdot r_{i}(i, k)+(1-\lambda) \cdot r_{i+1}^{o k_{1}}, \quad \lambda \in[0.5,1],
$$

$$
a_{i+1}(i, k)=\lambda \cdot a_{i}(i, k)+(1-\lambda) \cdot a_{i+1}^{o k_{1}}(i, k), \quad \lambda \in[0.5,1] .
$$


Step 6: if the number of iterations exceeds the maximum value or the number of consecutive iterations of the cluster center no longer changes, the calculation is stopped; otherwise, go to Step 3 to continue the calculation.

According to the implementation steps of the AP clustering algorithm, two problems arise in the clustering of customer demands. The first is that the AP clustering algorithm uses the Euclidean distance to calculate the distance between two data points. The weight of each data point to the distance is the same by default, so the construction of the similarity matrix cannot truly reflect the correlation of the demands [46]. The second problem is that the initial $P$ value is set manually, and the probability of each data point being a clustering center is the same, by default, which is obviously unreasonable.

Considering these two problems, this paper introduces a weighted network AP clustering algorithm for the cluster analysis of customer demands. This method uses intuitionistic fuzzy sets to transform the correlation of demands into quantized data to construct a weighted complex network and a weighted network model of customer demands to determine the initial $P$ value.

Atanassov proposed the intuitionistic fuzzy set [47]. A weighted network can be used to describe complex correlations of nodes. It can clearly describe the interaction strengths of individuals, where the weights represent the connection tightness of the nodes in the network [44]. In a weighted network, $V=\left\{v_{1}, v_{2}, \ldots, v_{n}\right\}$ represents the set of nodes, $\left(v_{i}, v_{i j}\right)$ represents the undirected edge between nodes $v_{i i}$ and $v_{i j}$, and $E \in\left\{\left(v_{i i}, v_{i j}\right): v_{i i}, v_{i j} \in V\right\}$ is the undirected edge set. The term $w_{i j}$ represents the weight of the undirected edge $\left(v_{i}, v_{j}\right)$, and $W=\left\{w_{i j}:\left(v_{i}, v_{j}\right) \in E\right\}$ is the weight set.

In a weighted network, the weights of the nodes reflect the interrelations and importance of each node in the network. The interaction strengths of the nodes are measured by the weights of the edges. In addition, the weights of the edges are related not only to directly connected nodes but also to neighboring nodes. Generally, the higher the number of neighboring nodes, the greater the strength of the interactions of the nodes [48]. Therefore, a weighted network used to analyze the distribution density of customer demand nodes should consider not just one factor, but all other relevant factors as well. In the customer demandweighted network model, five basic indicators reflect the connection density around the demand nodes $[49,50]$, as shown in Table 1.

According to the basic principles of an AP clustering algorithm based on a weighted network, the nodes are the customer demand units, the edges represent the correlations of the demand units, and the weights of the edges represent the similarities of the demand units. An undirected weighted network model of customer demand can thus be established. Therefore, the subjective influence of an initial deviation parameter determined by local density can be avoided in the AP clustering algorithm. The entire process can be described as follows:
Step 1: construct an intuitionistic fuzzy decision matrix. Let $\mathrm{CR}_{i}$ and $\mathrm{CR}_{j}$ be any two customer demands. The decision maker evaluates the similarity $u_{i j}$ and dissimilarity $v_{i j}$ between $\mathrm{CR}_{i}$ and $\mathrm{CR}_{j}$ according to the intuitive fuzzy evaluation scale. The evaluation ranges of $u_{i j}$ and $v_{i j}$ are both $[0,1]$, and $0 \leq u_{i j}+v_{i j} \leq 1$. Then, the decision maker's intuitionistic fuzzy decision matrix $Z$ for $n$ demands is

$$
Z=\left(d_{i j}\right)_{n \times n}=\left\{\begin{array}{cccc}
\left(u_{11}, v_{11}\right) & \left(u_{12}, v_{12}\right) & \ldots & \left(u_{1 j}, v_{1 j}\right) \\
\left(u_{21}, v_{21}\right) & \left(u_{22}, v_{22}\right) & \ldots & \left(u_{2 j}, v_{2 j}\right) \\
\vdots & \vdots & \ldots & \vdots \\
\left(u_{i 1}, v_{i 1}\right) & \left(u_{i 2}, v_{i 2}\right) & \ldots & \left(u_{n n}, v_{n n}\right)
\end{array}\right\},
$$

where the intuitionistic fuzzy number $d_{i j}=\left\langle u_{i j}, v_{i j}\right\rangle$. Step 2: solve the intuitionistic fuzzy similarity matrix. Let the intuitive fuzzy evaluation value between $\mathrm{CR}_{i}$ and $\mathrm{CR}_{j}$ be $d_{i j}=\left\langle u_{i j}, v_{i j}\right\rangle$. The similarity, dissimilarity, and hesitancy distances between $\mathrm{CR}_{i}$ and $\mathrm{CR}_{j}$, respectively, are as follows.

Similarity distance:

$$
d_{1}\left(a_{i}, a_{k}\right)=\sqrt[2]{\sum_{j=1}^{n}\left(u_{i j}-u_{k j}\right)^{2} .}
$$

Dissimilarity distance:

$$
d_{2}\left(a_{i}, a_{k}\right)=\sqrt[2]{\sum_{j=1}^{n}}\left(v_{i j}-v_{k j}\right)^{2} .
$$

Hesitation distance:

$$
d_{3}\left(a_{i}, a_{k}\right)=\sqrt[2]{\sum_{j=1}^{n}}\left(\pi_{i j}-\pi_{k j}\right)^{2} .
$$

The intuitive fuzzy similarity of $a_{i}$ and $a_{k}$ is described $\operatorname{by} \rho\left(a_{i}, a_{k}\right)=<\alpha_{i j}, \beta_{i j}>=<1-d_{1}\left(a_{i}, a_{k}\right)-d_{3}\left(a_{i}, a_{k}\right), d_{2}$ $\left(a_{i}, a_{k}\right)>$ :

$$
D=\left(\rho_{i j}\right)_{n \times n}=\left[\begin{array}{cccc}
\rho_{11} & \rho_{12} & \ldots & \rho_{1 j} \\
\rho_{21} & \rho_{22} & \ldots & \rho_{2 j} \\
\vdots & \vdots & \ldots & \vdots \\
\rho_{i 1} & \rho_{i 2} & \ldots & \rho_{n n}
\end{array}\right]
$$

Step 3: convert the intuitionistic fuzzy similarity matrix into a real matrix:

$$
F=\left(f_{i j}\right)_{n \times n}=\alpha_{i j}+\eta\left(1-\alpha_{i j}-\beta_{i j}\right),
$$

where $\eta$ is the satisfaction threshold, $\eta \in[0,1]$, such that 
TABLE 1: Weighted network indicators.

\begin{tabular}{lc}
\hline Indicators & Definition \\
\hline Connectivity & Number of edges to which a node is directly connected in a weighted network \\
Weighted degree & Sum of the weights of all edges directly connected to nodes in a weighted network \\
Weighted aggregation & Degree of aggregation around a node in a weighted network \\
$\begin{array}{l}\text { Agglomeration coefficient } \\
\text { Weighted network comprehensive eigenvalues }\end{array}$ & $\begin{array}{c}\text { Degree of connection between a node and its neighbors in a weighted network } \\
\text { Local distribution density around a node in a weighted network }\end{array}$ \\
\hline
\end{tabular}

$$
F=\left(f_{i j}\right)_{n \times n}=\left[\begin{array}{cccc}
f_{11} & f_{12} & \ldots & f_{1 j} \\
f_{21} & f_{22} & \ldots & f_{2 j} \\
\vdots & \vdots & \ldots & \vdots \\
f_{i 1} & f_{i 2} & \ldots & f_{n n}
\end{array}\right] .
$$

Step 4: use the demand units as the nodes, the correlations of the demand units as the edges in the weighted network, and the similarities of the demand units as the weights of the edges to establish an undirected weighted network model of customer demands.

Step 5: calculate the connectivity, weighted degree, weighted aggregation, clustering coefficient, and weighted network comprehensive eigenvalues of the nodes, respectively:

$$
D_{i}=\left|\left\{\left(v_{i}, v_{j}\right):\left(v_{i}, v_{j}\right) \in E, v_{i}, v_{j} \in V\right\}\right|,
$$

where $D_{i}$ represents the connectivity of node $i$;

$$
\mathrm{WD}_{i}=\sum_{\left(v_{i}, v_{j}\right) \in E} w_{i j},
$$

where $\mathrm{WD}_{i}$ represents the weighted degree of node $i$;

$$
\mathrm{WK}_{i}=\sum_{\left(v_{j}, v_{k} \in R\right)} w_{j k},
$$

where $\mathrm{WK}_{i}$ represents the weighted aggregation degree of node $i$, with $R=\left\{\left(v_{j}, v_{k}\right):\left(v_{i}, v_{j}\right) \in E,\left(v_{i}, v_{k}\right) \in E,\left(v_{i}\right.\right.$, $\left.\left.v_{k}\right) \in E, v_{i}, v_{j}, v_{k} \in V\right\}$;

$$
\mathrm{WC}_{i}=\frac{2 \mathrm{WK}_{i}}{\mathrm{WD}_{i}\left(\mathrm{WD}_{i}-1\right)}
$$

where $\mathrm{WC}_{i}$ represents the aggregation coefficient of node $i$; and

$$
\mathrm{WF}_{i}=\beta \mathrm{WC}_{i}+\frac{(1-\eta) \mathrm{WD}_{i}}{n}
$$

where $\mathrm{WF}_{i}$ represents the weighted network's comprehensive eigenvalue of node $i$, with $\beta$ taking the value range of $[0,1]$ and $n$ as the total number of nodes in the weighted network. Finally, by normalizing the integrated eigenvalues of the weighted network of nodes, the initial $P$ of each demand is determined.

Step 6: update the attraction and attribution values utilizing equations (4) to (8) until the stop condition is satisfied.
2.2. Cluster Analysis of Customer Demands for a Control Service System. To analyze customer demands, the example of a control service system for an iPSS for a water heater tank capping press is used. The capping press is for an enamel water tank liner of an air energy water heater, and it automatically presses the inner barrel and top cover in different diameters and lengths. The process flow diagram is depicted in Figure 3. The equipment uses a programmable logic controller (PLC) as the control core, an ABB robot as the top cover automatic feeding device, and a touch screen as the human-computer interaction interface.

The determination of customer demands can be divided into two stages. The first is the interview stage. When the water heater manufacturer purchases equipment, the designer obtains the customer's product and technical service demands by communicating with the customer group responsible for the purchase. After the interview, the questionnaire stage will be conducted. Use questionnaires to further obtain the use demands of maintenance personnel and operators.

Finally, the customers' demands for a control service system are categories into 35 types, as shown in Table 2.

Furthermore, these customer demands can be clustered into subject categories. The design teams evaluate the similarity and dissimilarity of the demand units, and the evaluation results can be averaged, as shown in Table 3.

According to equations (10) to (14), the intuitionistic fuzzy similarity matrix $D$ can be calculated as follows:

$$
D=\left[\begin{array}{ccccccccc}
1 & 0.243 & 0.102 & 0.097 & \ldots & 0.203 & 0.312 & 0.134 & 0.114 \\
0.243 & 1 & 0.741 & 0.183 & \ldots & 0.302 & 0.241 & 0.177 & 0.715 \\
0.102 & 0.741 & 1 & 0.162 & \ldots & 0.226 & 0.172 & 0.305 & 0.697 \\
0.097 & 0.183 & 0.162 & 1 & \ldots & 0.152 & 0.181 & 0.629 & 0.407 \\
0.203 & 0.302 & 0.226 & 0.152 & \ldots & 1 & 0.189 & 0.275 & 0.223 \\
0.312 & 0.241 & 0.172 & 0.181 & \ldots & 0.189 & 1 & 0.096 & 0.164 \\
\vdots & \vdots & \vdots & \vdots & \ldots & \vdots & \vdots & \vdots & \vdots \\
0.134 & 0.177 & 0.305 & 0.629 & \ldots & 0.275 & 0.096 & 1 & 0.304 \\
0.114 & 0.715 & 0.697 & 0.407 & \ldots & 0.223 & 0.164 & 0.304 & 1
\end{array}\right] .
$$

In the weighted network, the demand units are represented by the nodes, the correlations of the demand units are represented by the edges, and the similarities of the demand units are represented by the weights of the edges. An undirected weighted network model of customer demand can be built by selecting the Force Atlas layout in the Gephi software, as shown in Figure 4. 


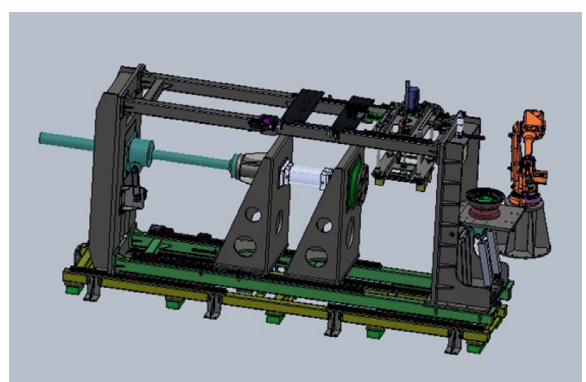

(a) (b)

FIgURE 3: The capping press process.

TABle 2: Customer demands for a control service system.

\begin{tabular}{|c|c|c|c|}
\hline Number & Name & Number & Name \\
\hline $\mathrm{Cr}_{1}$ & Information storage & $\mathrm{Cr}_{19}$ & Reset prompt \\
\hline $\mathrm{Cr}_{2}$ & Parameter settings & $\mathrm{Cr}_{20}$ & Operation monitoring \\
\hline $\mathrm{Cr}_{3}$ & Boot operation & $\mathrm{Cr}_{21}$ & Information query \\
\hline $\mathrm{Cr}_{4}$ & Error alarm & $\mathrm{Cr}_{22}$ & Maintenance cost \\
\hline $\mathrm{Cr}_{5}$ & Accident details & $\mathrm{Cr}_{23}$ & Graphical button size \\
\hline $\mathrm{Cr}_{6}$ & Workpiece information & $\mathrm{Cr}_{24}$ & Picture color \\
\hline $\mathrm{Cr}_{7}$ & Economical & $\mathrm{Cr}_{25}$ & Failure machine stop \\
\hline $\mathrm{Cr}_{8}$ & Button layout & $\mathrm{Cr}_{26}$ & Line label \\
\hline $\mathrm{Cr}_{9}$ & Selection error prompt & $\mathrm{Cr}_{27}$ & System upgrade \\
\hline $\mathrm{Cr}_{10}$ & Part stability & $\mathrm{Cr}_{28}$ & Program structure \\
\hline $\mathrm{Cr}_{11}$ & Part species & $\mathrm{Cr}_{29}$ & Program modification \\
\hline $\mathrm{Cr}_{12}$ & Full features & $\mathrm{Cr}_{30}$ & Part replacement \\
\hline $\mathrm{Cr}_{13}$ & Login authentication & $\mathrm{Cr}_{31}$ & Consistency check \\
\hline $\mathrm{Cr}_{14}$ & Three levels of login authority & $\mathrm{Cr}_{32}$ & Clear interface marking \\
\hline $\mathrm{Cr}_{15}$ & Operability & $\mathrm{Cr}_{33}$ & Equipment parameter query \\
\hline $\mathrm{Cr}_{16}$ & Intensity & $\mathrm{Cr}_{34}$ & Operation feedback \\
\hline $\mathrm{Cr}_{17}$ & Model switching & $\mathrm{Cr}_{35}$ & Error reset \\
\hline $\mathrm{Cr}_{18}$ & Error self-diagnosis & - & - \\
\hline
\end{tabular}

TABle 3: Customer demands: evaluation results.

\begin{tabular}{|c|c|c|c|c|c|c|c|}
\hline & $\mathrm{Cr}_{1}$ & $\mathrm{Cr}_{2}$ & $\mathrm{Cr}_{3}$ & $\ldots$ & $\mathrm{Cr}_{33}$ & $\mathrm{Cr}_{34}$ & $\mathrm{Cr}_{35}$ \\
\hline $\mathrm{Cr}_{1}$ & $(1,0)$ & $(0.23,0.72)$ & $(0.12,0.76)$ & $\ldots$ & $(0.32,058)$ & $(0.16,0.67)$ & $(0.10,0.82)$ \\
\hline $\mathrm{Cr}_{2}$ & $(0.23,0.72)$ & $(1,0)$ & $(0.71,0.16)$ & $\ldots$ & $(0.26,0.60)$ & $(0.18,0.69)$ & $(0.75,0.12)$ \\
\hline $\mathrm{Cr}_{3}$ & $(0.12,0.76)$ & $(0.71,0.16)$ & $(1,0)$ & $\ldots$ & $(0.12,0.69)$ & $(0.34,0.58)$ & $(0.67,0.18)$ \\
\hline $\mathrm{Cr}_{4}$ & $(0.08,0.82)$ & $(0.23,0.59)$ & $(0.12,0.80)$ & $\ldots$ & $(0.12,0.72)$ & $(0.69,0.23)$ & $(0.40,0.48)$ \\
\hline$\ldots$ & $\ldots$ & $\ldots$ & $\ldots$ & $\ldots$ & & & \\
\hline $\mathrm{Cr}_{32}$ & $(0.18,0.67)$ & $(0.32,0.59)$ & $(0.24,0.71)$ & $\ldots$ & $(0.19,0.68)$ & $(0.28,0.64)$ & $(0.22,0.58)$ \\
\hline $\mathrm{Cr}_{33}$ & $(0.32,058)$ & $(0.26,0.60)$ & $(0.12,0.69)$ & $\ldots$ & $(1,0)$ & $(0.09,0.72)$ & $(0.15,0.69)$ \\
\hline $\mathrm{Cr}_{34}$ & $(0.16,0.67)$ & $(0.18,0.69)$ & $(0.34,0.58)$ & $\ldots$ & $(0.09,0.72)$ & $(1,0)$ & $(0.31,0.64)$ \\
\hline $\mathrm{Cr}_{35}$ & $(0.10,0.82)$ & $(0.75,0.12)$ & $(0.67,0.18)$ & $\ldots$ & $(0.22,0.58)$ & $(0.31,0.64)$ & $(1,0)$ \\
\hline
\end{tabular}

In the undirected weighted network model of customer demand, the parameter $\beta$ is 0.5 according to equations (16) to $(20)$. The calculation of the network attribute value of every node is shown in Table 4.

Since the range of the initial $P$ value in the AP clustering algorithm is $[0,1]$, the initial $P$ value of the customer requirements $\mathrm{Cr}_{1}, \mathrm{Cr}_{2}, \ldots, \mathrm{Cr}_{35}$ can be assumed to be $p_{1}, p_{2}, \ldots, p_{35}$. By adopting the normalization method to process the weighted network's comprehensive feature value of each node, the initial $P$ value of every customer demand can be obtained, as shown in Table 5 .

To facilitate calculation and programming, 35 random coordinate points are set to correspond to customer demands $\mathrm{Cr}_{1}, \mathrm{Cr}_{2}, \ldots, \mathrm{Cr}_{35}$. The values of the initial deviation parameters for every demand are shown in Table 5, where the maximum number of iterations is set to 500 and the 


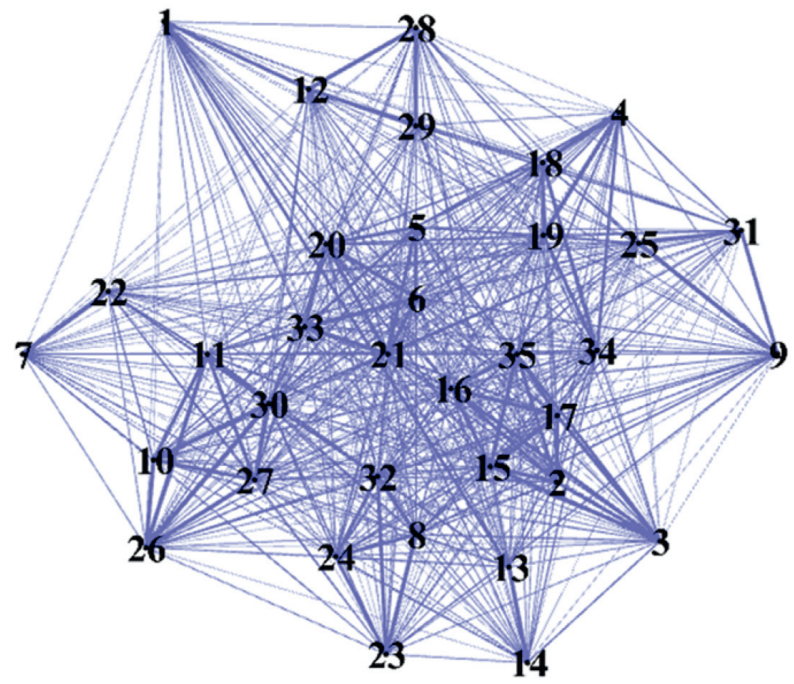

FIGURE 4: Undirected weighted network model of customer demands.

TABLE 4: Eigenvalues of the weighted network nodes.

\begin{tabular}{|c|c|c|c|c|c|}
\hline Node & Degree & $\begin{array}{c}\text { Weighted degree } \\
\text { WD }\end{array}$ & $\begin{array}{c}\text { Weighted } \\
\text { aggregation }\end{array}$ & $\begin{array}{l}\text { Aggregation coefficient } \\
\text { WC }\end{array}$ & $\begin{array}{l}\text { Weighted network's comprehensive } \\
\text { eigenvalues }\end{array}$ \\
\hline $\mathrm{Cr}_{1}$ & 35 & 6.3 & 132.2 & 7.92 & 4.05 \\
\hline $\mathrm{Cr}_{2}$ & 35 & 8.9 & 129.8 & 3.69 & 1.97 \\
\hline $\mathrm{Cr}_{3}$ & 35 & 8.1 & 130.4 & 4.53 & 2.38 \\
\hline $\mathrm{Cr}_{4}$ & 35 & 7.4 & 131.1 & 5.54 & 2.87 \\
\hline $\mathrm{Cr}_{5}$ & 35 & 8.0 & 130.5 & 4.66 & 2.44 \\
\hline $\mathrm{Cr}_{6}$ & 35 & 8.5 & 130.0 & 4.08 & 2.16 \\
\hline $\mathrm{Cr}_{7}$ & 35 & 5.5 & 133.0 & 10.75 & 5.45 \\
\hline $\mathrm{Cr}_{8}$ & 35 & 8.2 & 130.3 & 4.41 & 2.18 \\
\hline $\mathrm{Cr}_{9}$ & 35 & 7.0 & 131.5 & 6.26 & 3.23 \\
\hline $\mathrm{Cr}_{10}$ & 35 & 7.8 & 130.7 & 4.93 & 2.57 \\
\hline $\mathrm{Cr}_{11}$ & 35 & 8.4 & 130.1 & 4.19 & 2.21 \\
\hline $\mathrm{Cr}_{12}$ & 35 & 7.3 & 131.2 & 5.71 & 2.96 \\
\hline $\mathrm{Cr}_{13}$ & 35 & 6.8 & 131.7 & 6.68 & 3.44 \\
\hline $\mathrm{Cr}_{14}$ & 35 & 6.2 & 132.3 & 8.21 & 4.19 \\
\hline $\mathrm{Cr}_{15}$ & 35 & 9.9 & 128.6 & 2.92 & 1.60 \\
\hline $\mathrm{Cr}_{16}$ & 35 & 9.8 & 128.7 & 2.98 & 1.63 \\
\hline $\mathrm{Cr}_{17}$ & 35 & 9.7 & 128.8 & 3.05 & 1.66 \\
\hline $\mathrm{Cr}_{18}$ & 35 & 8.1 & 130.4 & 4.53 & 2.38 \\
\hline $\mathrm{Cr}_{19}$ & 35 & 8.2 & 130.3 & 4.41 & 2.32 \\
\hline $\mathrm{Cr}_{20}$ & 35 & 8.8 & 129.7 & 3.78 & 2.01 \\
\hline $\mathrm{Cr}_{21}$ & 35 & 9.6 & 128.9 & 3.12 & 1.69 \\
\hline $\mathrm{Cr}_{22}$ & 35 & 6.3 & 132.2 & 7.92 & 4.05 \\
\hline $\mathrm{Cr}_{23}$ & 35 & 7.3 & 131.2 & 5.71 & 2.96 \\
\hline $\mathrm{Cr}_{24}$ & 35 & 7.9 & 130.6 & 4.79 & 2.51 \\
\hline $\mathrm{Cr}_{25}$ & 35 & 7.2 & 131.3 & 5.88 & 3.04 \\
\hline $\mathrm{Cr}_{26}$ & 35 & 7.2 & 131.3 & 5.88 & 3.04 \\
\hline $\mathrm{Cr}_{27}$ & 35 & 8.7 & 129.8 & 3.88 & 2.06 \\
\hline $\mathrm{Cr}_{28}$ & 35 & 6.7 & 131.8 & 6.90 & 3.54 \\
\hline $\mathrm{Cr}_{29}$ & 35 & 6.5 & 132.0 & 7.38 & 3.78 \\
\hline $\mathrm{Cr}_{30}$ & 35 & 10.2 & 128.3 & 2.73 & 1.51 \\
\hline $\mathrm{Cr}_{31}$ & 35 & 6.4 & 132.1 & 7.64 & 3.91 \\
\hline $\mathrm{Cr}_{32}$ & 35 & 9.2 & 129.3 & 3.43 & 1.84 \\
\hline $\mathrm{Cr}_{33}$ & 35 & 7.1 & 131.4 & 6.07 & 3.13 \\
\hline $\mathrm{Cr}_{34}$ & 35 & 8.7 & 129.8 & 3.88 & 2.06 \\
\hline $\mathrm{Cr}_{35}$ & 35 & 9.2 & 129.3 & 3.43 & 1.84 \\
\hline
\end{tabular}


TABLE 5: Initial $P$ value of every customer demand.

\begin{tabular}{lccccccccccc}
\hline$p_{1}$ & $p_{2}$ & $p_{3}$ & $p_{4}$ & $p_{5}$ & $p_{6}$ & $p_{7}$ & $p_{8}$ & $p_{9}$ & $p_{10}$ & $p_{11}$ & $p_{12}$ \\
0.89 & 0.17 & 0.31 & 0.48 & 0.33 & 0.24 & 1 & 0.24 & 0.61 & 0.38 & 0.25 & 0.52 \\
\hline$p_{13}$ & $p_{14}$ & $p_{15}$ & $p_{16}$ & $p_{17}$ & $p_{18}$ & $p_{19}$ & $p_{20}$ & $p_{21}$ & $p_{22}$ & $p_{23}$ & $p_{24}$ \\
0.68 & 0.95 & 0.04 & 0.05 & 0.06 & 0.31 & 0.29 & 0.18 & 0.07 & 0.9 & 0.52 & 0.36 \\
\hline$p_{25}$ & $p_{26}$ & $p_{27}$ & $p_{28}$ & $p_{29}$ & $p_{30}$ & $p_{31}$ & $p_{32}$ & $p_{33}$ & $p_{34}$ & $p_{35}$ & - \\
0.54 & 0.54 & 0.2 & 0.72 & 0.80 & 0 & 0.85 & 0.13 & 0.58 & 0.2 & 0.13 & - \\
\hline
\end{tabular}

number of consecutive iterations of the cluster center without a change is set to 50 . The value of $\lambda$ is set to 0.5 in Matlab R2014b. Figure 5 shows the results.

In Figure 5, when $\lambda=0.5$, after 40 iterations, the fitness value becomes stable at 22.20, indicating that the clustering center no longer changes and the value of $\lambda$ is reasonable. There are nine clusters, where the dots represent demand items, demands in the same category are connected by straight lines, and different categories are displayed in various colors. According to the coordinate points corresponding to each demand, the customer demands displayed in Table 1 can be grouped into nine categories, $\left\{\mathrm{Cr}_{1}, \mathrm{Cr}_{13}\right.$, $\left.\mathrm{Cr}_{14}\right),\left(\mathrm{Cr}_{2}, \mathrm{Cr}_{3}, \mathrm{Cr}_{15}, \mathrm{Cr}_{16}, \mathrm{Cr}_{17}, \mathrm{Cr}_{35}\right),\left(\mathrm{Cr}_{4}, \mathrm{Cr}_{18}, \mathrm{Cr}_{19}\right.$, $\left.\mathrm{Cr}_{34}\right),\left(\mathrm{Cr}_{5}, \mathrm{Cr}_{6}, \mathrm{Cr}_{20}, \mathrm{Cr}_{21}, \mathrm{Cr}_{33}\right),\left(\mathrm{Cr}_{7}, \mathrm{Cr}_{22}\right),\left(\mathrm{Cr}_{8}, \mathrm{Cr}_{23}\right.$, $\left.\mathrm{Cr}_{24}, \mathrm{Cr}_{32}\right),\left(\mathrm{Cr}_{9}, \mathrm{Cr}_{25}, \mathrm{Cr}_{31}\right),\left(\mathrm{Cr}_{27}, \mathrm{Cr}_{10}, \mathrm{Cr}_{11}, \mathrm{Cr}_{26}, \mathrm{Cr}_{30}\right)$, $\left.\left(\mathrm{Cr}_{12}, \mathrm{Cr}_{28}, \mathrm{Cr}_{29}\right)\right\}$. The customer demands for the control service system can then be divided into nine different subject categories, as shown in Table 6.

\section{Function Domain Determination for a Control Service System}

3.1. Overview of QFD. QFD, a typical customer-driven design method, was first proposed by Mizuno and Akao [51]. The basic display tool of QFD is the house of quality, an intuitive matrix framework for the conversion of customer demands [52]. As a customer-driven product development method, it is a simple and logical demand conversion tool. At present, the QFD configuration process can be broken down into four stages: the product planning quality house, the parts' development quality house, the process planning quality house, and the production planning quality house (see Figure 6). These four stages use various expansion tables to transform the important parts of the demands downward, step by step, to ensure that the product design process does not deviation from the customer's requirements.

In QFD, the correlation matrix is used to express the complex relation between every demand item and every technical feature of the product [53]. After determining the correlations between a customer's demands and the product's technical characteristics, the importance of the latter can be further determined. As shown in Table 7, a set of symbols is generally used to indicate the degree of correlation.

Furthermore, the product's technical features can be calculated by the equations

$$
\begin{aligned}
& \operatorname{TIR}_{j}=\sum_{i=1}^{n} \operatorname{CIR}_{i} \times R_{i j},(i=1,2, \ldots, n ; j=1,2, \ldots, m), \\
& \operatorname{TIR}_{j}^{\prime}=\frac{\operatorname{TIR}_{j}}{\sum \operatorname{TIR}_{j}},(j=1,2, \ldots, m),
\end{aligned}
$$

where $n$ represents the number of customer demands, $m$ represents the number of the product's technical features, $\mathrm{CIR}_{i}$ is the weight of the $i$ th customer demand item, $R_{i j}$ is the value of the correlation symbol between the $i$ th customer demand item and the $j$ th product technical feature item, $\mathrm{TIR}_{j}$ is the weight of the $j$ th product technical feature item, and $\mathrm{TIR}_{j}^{\prime}$ is the relative weight of the $j$ th product technical feature item.

3.2. Function Planning for a Control Service System. After the customer demands have been standardized, a mapping analysis between the demand domain and the function domain is carried out. The system's functional characteristics are the customer's requirements, described in engineering and technical language. The control service system usually takes into consideration the process requirements, performance requirements, working environment, industry standards, and so on, as well as functional characteristics. For example, the equipment must be able to process multiple products. Therefore, the system should be compatible with multiple models. The customer demands include the realtime display of workpiece information. Therefore, system function monitoring is required. The customer demands also involve low labor intensity and the ability to convert quickly between different models of products. Therefore, the system must have the capability of automatically switching models. Table 8 shows the functional characteristics of the system, following the analysis.

In addition, some requirements in the customer demand domain have constraints on other functional features, although they might not individually correspond to specific functional features. For example, economic requirements hold throughout the entire design process because cost factors must be considered for every function. Therefore, a HoQ of system functions should be built to analyze the correlations between customer demands and system functional characteristics and clarify the system design's focus (see Figure 7). 


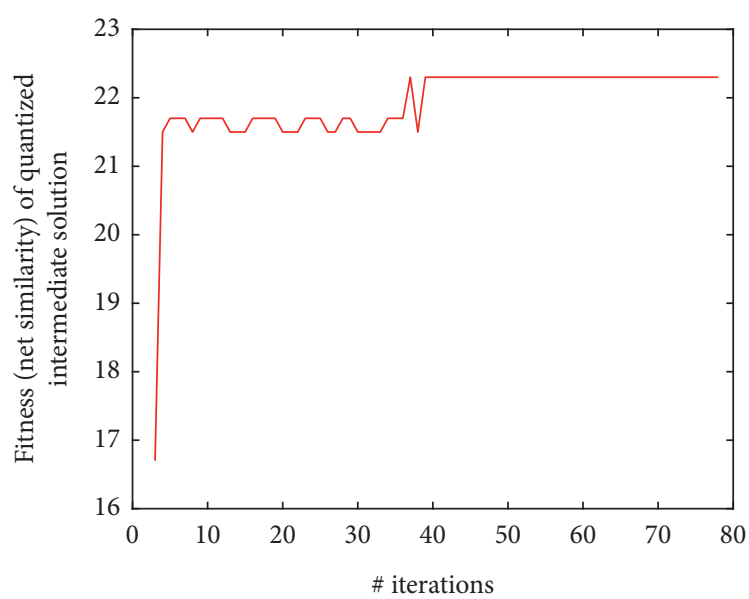

(a)

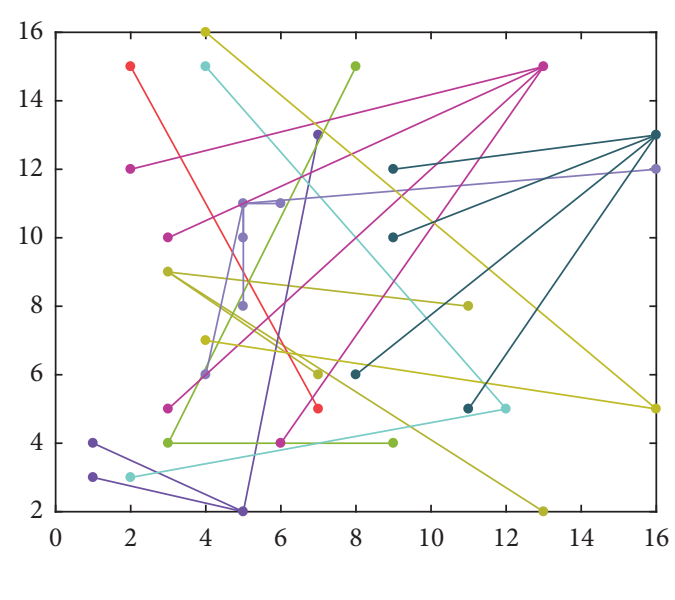

(b)

Figure 5: Clustering of customer demands.

TABle 6: Architecture of customer demands.

\begin{tabular}{|c|c|c|}
\hline Primary customer demands & Secondary customer demands & Tertiary customer demands \\
\hline Customer demands for a control service system & $\begin{array}{c}\text { Information security, } \mathrm{CR}_{1} \\
\text { Operability, } \mathrm{CR}_{2} \\
\text { Alarm prompt, } \mathrm{CR}_{3} \\
\text { Information query, } \mathrm{CR}_{4} \\
\text { User-friendly interface, } \mathrm{CR}_{5} \\
\text { System program, } \mathrm{CR}_{6} \\
\text { Error-proof design, } \mathrm{CR}_{7} \\
\text { Maintainability, } \mathrm{CR}_{8} \\
\text { Economy, } \mathrm{CR}_{9}\end{array}$ & $\begin{array}{c}\mathrm{Cr}_{1}, \mathrm{Cr}_{13}, \mathrm{Cr}_{14} \\
\mathrm{Cr}_{2}, \mathrm{Cr}_{3}, \mathrm{Cr}_{15}, \mathrm{Cr}_{16}, \mathrm{Cr}_{17}, \mathrm{Cr}_{35} \\
\mathrm{Cr}_{4}, \mathrm{Cr}_{18}, \mathrm{Cr}_{19}, \mathrm{Cr}_{34} \\
\mathrm{Cr}_{5}, \mathrm{Cr}_{6}, \mathrm{Cr}_{20}, \mathrm{Cr}_{21}, \mathrm{Cr}_{33} \\
\mathrm{Cr}_{8}, \mathrm{Cr}_{23}, \mathrm{Cr}_{24}, \mathrm{Cr}_{32} \\
\mathrm{Cr}_{12}, \mathrm{Cr}_{28}, \mathrm{Cr}_{29} \\
\mathrm{Cr}_{9}, \mathrm{Cr}_{25}, \mathrm{Cr}_{31} \\
\mathrm{Cr}_{1}, \mathrm{Cr}_{10}, \mathrm{Cr}_{11}, \mathrm{Cr}_{26}, \mathrm{Cr}_{30} \\
\mathrm{Cr}_{7}, \mathrm{Cr}_{22}\end{array}$ \\
\hline
\end{tabular}

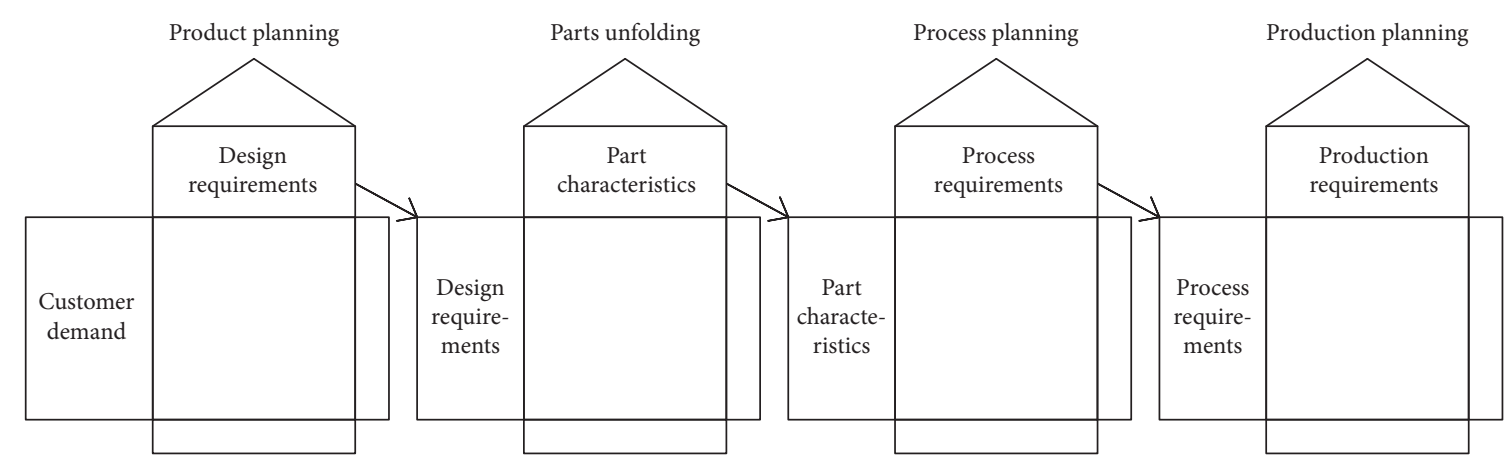

Figure 6: Four stages of QFD configuration.

TABLE 7: Evaluation and decision table for the correlations between the demand and technical characteristics.

\begin{tabular}{lcc}
\hline Symbol & Value & Meaning \\
\hline & 5 & Strong correlation between the demand and technical characteristics \\
$\square$ & 3 & Medium correlation between the demand and technical characteristics \\
$\triangle$ & 1 & Weak correlation between the demand and technical characteristics \\
\hline
\end{tabular}

Following the functional planning output of the HoQ, the designer can clarify major and minor points in the design process, focus on the main points, and avoid deviating from the customer's directions due to personal experience and cognitive limitations. The control service system requires nine functions: $\mathrm{FR}_{1}$, compatibility with multiple models, 
TABLE 8: Functional characteristics of the control service system.

\begin{tabular}{|c|c|c|c|c|c|}
\hline Name & $\mathrm{FR}_{1}$ & $\mathrm{FR}_{2}$ & $\mathrm{FR}_{3}$ & $\mathrm{FR}_{4}$ & $\mathrm{FR}_{5}$ \\
\hline Paraphrase & Compatible with multiple models & Automatic switching model & User login & Alarm function & Device driven \\
\hline $\begin{array}{l}\text { Name } \\
\text { Paraphrase }\end{array}$ & $\begin{array}{c}\mathrm{FR}_{6} \\
\text { Automatic feeding }\end{array}$ & $\begin{array}{c}\mathrm{FR}_{7} \\
\text { Multiple working modes }\end{array}$ & $\begin{array}{c}\mathrm{FR}_{8} \\
\text { Monitoring function }\end{array}$ & $\begin{array}{c}\mathrm{FR}_{9} \\
\text { Humanized design }\end{array}$ & $\begin{array}{l}- \\
-\end{array}$ \\
\hline
\end{tabular}

\begin{tabular}{|c|c|c|c|c|c|c|c|c|c|c|}
\hline \multirow{3}{*}{ Demand } & \multirow[b]{3}{*}{ Weights } & \multicolumn{9}{|c|}{ System features } \\
\hline & & \multirow{2}{*}{$\begin{array}{l}\text { Compatible } \\
\text { with multiple } \\
\text { models }\end{array}$} & \multirow{2}{*}{$\begin{array}{l}\text { Automatic } \\
\text { model } \\
\text { switching }\end{array}$} & \multirow{2}{*}{ User login } & \multirow{2}{*}{$\begin{array}{l}\text { Alarm } \\
\text { function }\end{array}$} & \multirow{2}{*}{ Device driver } & \multirow{2}{*}{$\begin{array}{l}\text { Automatic } \\
\text { feeding }\end{array}$} & \multirow{2}{*}{$\begin{array}{c}\text { Multiple } \\
\text { working } \\
\text { modes }\end{array}$} & \multirow{2}{*}{$\begin{array}{l}\text { Monitoring } \\
\text { function }\end{array}$} & \multirow{2}{*}{$\begin{array}{c}\text { Humanized } \\
\text { design }\end{array}$} \\
\hline & & & & & & & & & & \\
\hline Information security & 0.0812 & $\triangle$ & & 0 & & & & & $\triangle$ & $\square$ \\
\hline Operability & 0.1882 & \begin{tabular}{|l}
$\square$ \\
\end{tabular} & $C$ & \begin{tabular}{|l} 
\\
\end{tabular} & & $\square$ & $\square$ & ) & & $\square$ \\
\hline Alarm prompt & 0.1637 & $\triangle$ & & & ) & $\square$ & & & & \\
\hline Information query & 0.0977 & & & & & $\triangle$ & $\square$ & & ) & $\square$ \\
\hline Pleasant interface & 0.0636 & & $\square$ & $\triangle$ & & & & 0 & $\square$ & 0 \\
\hline System program & 0.0783 & & 0 & & & $\square$ & & $\square$ & & \\
\hline Error-proof design & 0.0737 & $\square$ & $\square$ & & $\square$ & & $\square$ & & & \\
\hline Maintainability & 0.1922 & $\square$ & & & $\triangle$ & & & & & \\
\hline Economy & 0.0613 & $\triangle$ & & & $\square$ & & & & & \\
\hline \multicolumn{2}{|l|}{ Weights } & 4.0499 & 1.7444 & 1.0342 & 1.4157 & 2.6558 & 1.0788 & 1.4939 & 0.7605 & 1.4193 \\
\hline \multicolumn{2}{|c|}{ Relative weights } & 0.2587 & 0.1114 & 0.0661 & 0.0905 & 0.1696 & 0.0689 & 0.0954 & 0.0486 & 0.0907 \\
\hline \multicolumn{2}{|c|}{ Target expectations } & $\begin{array}{l}\text { Meet contract } \\
\text { and functional } \\
\text { requirements }\end{array}$ & $\begin{array}{c}\text { Meet } \\
\text { functional } \\
\text { requirements }\end{array}$ & $\begin{array}{l}\text { Meet contract } \\
\text { and functional } \\
\text { requirements }\end{array}$ & $\begin{array}{l}\text { Meet contract } \\
\text { and functional } \\
\text { requirements }\end{array}$ & $\begin{array}{l}\text { Meet contract } \\
\text { and functional } \\
\text { requirements }\end{array}$ & $\begin{array}{l}\text { Meet contract } \\
\text { and functional } \\
\text { requirements }\end{array}$ & $\begin{array}{l}\text { Meet contract } \\
\text { and functional } \\
\text { requirements }\end{array}$ & $\begin{array}{c}\text { Meet } \\
\text { functional } \\
\text { requirements }\end{array}$ & $\begin{array}{c}\text { Meet } \\
\text { functional } \\
\text { requirements }\end{array}$ \\
\hline
\end{tabular}

FIgURE 7: HoQ of the functional planning for the control service system.

$\mathrm{FR}_{2}$, automatic model switching, $\mathrm{FR}_{3}$, a user login, $\mathrm{FR}_{4}$, an alarm function, $\mathrm{FR}_{5}$, being device driven, $\mathrm{FR}_{6}$, automatic feeding, $\mathrm{FR}_{7}$, multiple working modes, $\mathrm{FR}_{8}$, a monitoring function, and $\mathrm{FR}_{9}$, humanized design. The relative importance levels of each functional characteristic are shown in Table 9.

\section{Structure Domain Determination for the Control Service System}

4.1. Overview of $A D$. The core of $\mathrm{AD}$ is the domain. According to Suh, the domain is the boundary of four design activities with different types and different modes in the product design phase [54]. The domains in axiomatic theory are the customer domain, the function domain, the structure domain, and the process domain. Between two adjacent design domains, the left domain represents the "what," that is, the purpose, and the right domain represents the "how," that is, the method that satisfies the left domain. The hierarchical structure and zigzag mapping are the core methods of the $\mathrm{AD}$ design process [55]. As depicted in Figure 8 , the hierarchical structure describes the relation of various elements within the domain, and the zigzag mapping represents the mapping of the domains.
Figure 8(a) illustrates the hierarchical structure of collection self-decomposition in the domain. A group of subsystems can be composed of elements in the domain according to certain rules. Here, a top-down method is used to decompose the abstract total function into subfunctions, layer by layer, until the final design is produced. The correlations of the functional, structural, and process domains are described according to the zigzag mapping in Figure 8 (b). The zigzag mapping is a top-down approach in the form of a $Z$, and it repeats the mapping of the same and different levels in every domain until the previous domain can no longer be decomposed.

To judge the reasonability of the design process, AD theory proposes a design axiom. While mapping the function domain to the structure domain, the designer can judge the appropriateness of the mapping according to the design axioms. The entire mapping can be described as

$$
\{\mathrm{FR}\}_{m \times 1}=A_{m \times n}\{\mathrm{DP}\}_{n \times 1} \text {, }
$$

where $\{\mathrm{FR}\}_{m \times 1}$ represents the FRs, $\{\mathrm{DP}\}_{n \times 1}$ represents the DPs, and $A_{m \times n}$ represents the design matrix, which can be expressed as 
TABLE 9: Relative importance of system functional characteristics.

\begin{tabular}{lccccccccc}
\hline Features & $\mathrm{FR}_{1}$ & $\mathrm{FR}_{2}$ & $\mathrm{FR}_{3}$ & $\mathrm{FR}_{4}$ & $\mathrm{FR}_{5}$ & $\mathrm{FR}_{6}$ & $\mathrm{FR}_{7}$ & $\mathrm{FR}_{8}$ & $\mathrm{FR}_{9}$ \\
\hline \multirow{2}{*}{ Relative weight } & $\mu_{1}$ & $\mu_{2}$ & $\mu_{3}$ & $\mu_{4}$ & $\mu_{5}$ & $\mu_{6}$ & $\mu_{7}$ & $\mu_{8}$ & $\mu_{9}$ \\
& 0.2587 & 0.1114 & 0.0661 & 0.0905 & 0.0169 & 0.0689 & 0.0954 & 0.0486 & 0.0907 \\
\hline
\end{tabular}

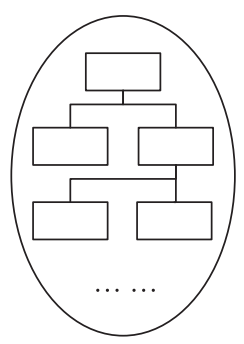

(a)

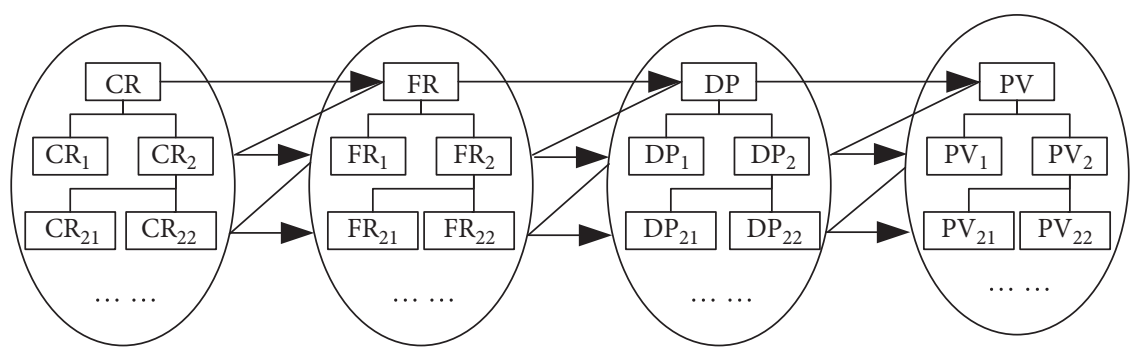

(b)

Figure 8: (a) Hierarchy and (b) zigzag mapping of AD.

$$
A_{m \times n}=\left[\begin{array}{cccc}
A_{11} & A_{12} & \ldots & A_{1 n} \\
A_{21} & A_{22} & \ldots & A_{2 n} \\
\vdots & \vdots & \ldots & \vdots \\
A_{m 1} & A_{m 2} & \ldots & A_{m n}
\end{array}\right]
$$

where the matrix elements are determined by $A_{i j}=\left(\partial F R_{i}\right) /$ $\left(\partial D P_{j}\right)(i=1,2, \ldots, m ; j=1,2, \ldots, n)$.

In an actual design, the numbers of FRs and DPs will not be the same. As shown in Table 10, given the relation between the numbers of FRs and the number of DPs, the design can be split into an ideal design, a redundant design, and a coupling design.

4.2. House of Quality for Risk Prediction. Once the basic structure of a control service system is described, highrisk modules in the structure domain can be predicted and analyzed to determine potential failure modes and analyze the possible consequences. These measures can be taken in advance. Because the importance of the elements in the domain cannot be evaluated in $\mathrm{AD}$, this paper introduces a risk prediction HoQ model. This model transmits the decomposition and mapping results of the AD functional and structural domains to the HoQ, builds a risk prediction HoQ, and proposes the ERPN to measure every structural module and clarify the key points of the process.

The concept of ERPN is based on risk probability number. Taking into account the importance of the system functions, the system structure can be optimized to determine measures to reduce the chance of potential failure. The formula for the ERPN is

$$
\mathrm{ERPN}=\mu_{j} \cdot I_{k} \cdot S \cdot O \cdot D,
$$

where $\mu_{j}$ is the relative weight of the $j$ th system function characteristic in the HoQ, $I_{k}$ is the weight of the $k$ th subfunction characteristic in the risk prediction HoQ, and $S$ is the severity (see Table 11).

Table 12 shows the scoring criteria for the frequency $O$.
Table 13 shows the scoring criteria for the degree of detection $D$.

4.3. Structure Domain Solution of the Control Service System. The system's functional characteristics are only a visual description of the control system and do not correspond directly to the basic composition of the system. Therefore, a practical system design is impossible. According to the principle of functional decomposition mapping in $\mathrm{AD}$, the basic structure of the water heater liner top press control system can be determined through the zigzag mapping. Functions can then be transformed from the conceptual to the specific, and an overall system structure can be built. Finally, when all the basic components of the system are worked out, the structure can be optimized by establishing a HoQ for risk prediction.

In the example of the decomposition map of the automatic switching model function, $\mathrm{FR}_{2}$, the corresponding basic structure module and risk prediction of the basic structure in question are proposed. The water heater tank capping press has an inner liner press and an inner liner top cover automatic feeding device. The automatic model switching function, $\mathrm{FR}_{2}$, requires that the automatic feeding device of the top cover recognize different workpiece types and automatically feed different types of top covers. According to the equipment's execution sequence, $\mathrm{FR}_{2}$ can be decomposed into two subfunctions, such as sending the workpiece model, $\mathrm{FR}_{21}$, and receiving the workpiece model, $\mathrm{FR}_{22}$. The corresponding mapping structures are the model identification module of the PLC system, $\mathrm{DP}_{21}$, and the model identification module of the ABB robot control system, $\mathrm{DP}_{22}$. The design equation of the mapping is thus

$$
\left[\begin{array}{l}
\mathrm{FR}_{21} \\
\mathrm{FR}_{22}
\end{array}\right]=\left[\begin{array}{ll}
1 & 0 \\
1 & 1
\end{array}\right]\left[\begin{array}{l}
\mathrm{DP}_{21} \\
\mathrm{DP}_{22}
\end{array}\right]
$$

The subfunctions of the sent workpiece model, $\mathrm{FR}_{21}$, can be decomposed into the model selection carrier, $\mathrm{FR}_{211}$, and the workpiece model selection item, $\mathrm{FR}_{212}$, recognizes the selected workpiece model of the PLC system, $\mathrm{FR}_{213}$, and transmits the 
TABLE 10: Ideal, redundant, and coupling designs.

\begin{tabular}{llc}
\hline Design name & \multicolumn{1}{c}{ Condition } & Design matrix \\
\hline Ideal design & Number of FRs $=$ number of DPs & Diagonal matrix \\
Redundant design & Number of FRs $<$ number of DPs & Triangular matrix \\
Coupling design & Number of FRs $>$ number of DPs & Nontriangular matrix and nondiagonal matrix \\
\hline
\end{tabular}

TABLE 11: Severity $(S)$ scoring criteria.

\begin{tabular}{|c|c|c|}
\hline Harm & Assessment criteria: severity of the impact on the system & Severity level \\
\hline No warning hazard & No alarm is issued when the equipment is faulty and the control system is completely out of order & 10 \\
\hline Warning hazard & Alarm when the equipment is faulty and the control system fails & 9 \\
\hline Very serious & Has a serious impact on the control system and the system is difficult to repair & 8 \\
\hline Serious & Has a serious impact on the control system, but the system can be partially repaired & 7 \\
\hline Medium & Has a certain impact on the control system, but the system can be repaired & 6 \\
\hline Low & Has a certain impact on the control system, but the system can be repaired completely & 5 \\
\hline Very low & Has less impact on the control system and the system can be repaired more quickly & 4 \\
\hline Slight & The impact on the control system is small, and the system can be repaired quickly & 3 \\
\hline Very & The impact on the control system is very slight, and the system can be easily repaired & 2 \\
\hline Nothing & No impact on the control system, and the system can work normally & 1 \\
\hline
\end{tabular}

TABLe 12: Frequency $(O)$ scoring criteria.

\begin{tabular}{lcc}
\hline Possibility of failure & Evaluation criteria: frequency of occurrence & Frequency \\
\hline \multirow{2}{*}{ Very high } & Greater than $1 / 2$ & 10 \\
& About $1 / 3$ & 9 \\
\hline \multirow{2}{*}{ High } & About 1/8 & 8 \\
& About $1 / 20$ & 7 \\
Moderate & About $1 / 80$ & 5 \\
& About $1 / 400$ & 4 \\
Low & About $1 / 2000$ & 3 \\
& About $1 / 15,000$ & 2 \\
\hline Very low & About $1 / 150,000$ & 1 \\
\hline
\end{tabular}

TABle 13: Scoring criteria for the degree of detection $D$.

\begin{tabular}{|c|c|c|}
\hline Detectability level & Evaluation criteria: the possibility of detecting the cause of system failures in the prior art & Level \\
\hline Infinitesimal & The prior art cannot detect the cause of the failure of the control system & 10 \\
\hline Very tiny & Existing technology has difficulty detecting the cause of the failure of the control system & 9 \\
\hline Tiny & Existing technology has more difficult detecting the cause of the failure of the control system & 8 \\
\hline Very low & Need a control system designer to investigate the cause of the fault & 7 \\
\hline Low & A technician can discover the cause of the failure & 6 \\
\hline Medium & The control system has alarm tips, but does not display fault information & 5 \\
\hline Higher & The control system has alarm tips and displays fault information & 4 \\
\hline High & The cause of the fault can be determined by a simple test instrument & 3 \\
\hline Very high & The cause of the failure can be visually identified & 2 \\
\hline Almost certainly & The cause of the fault can be detected almost certainly & 1 \\
\hline
\end{tabular}

workpiece model information, $\mathrm{FR}_{214}$. The working principle involves receiving the input signal of the workpiece model, generating a control signal after the program is run, and then issuing a control command. The corresponding mapping structures are the selection screen, $\mathrm{DP}_{211}$, the workpiece selection list, $\mathrm{DP}_{212}$, the PLC model judgment program, $\mathrm{DP}_{213}$, and PLC workpiece model information output point, $\mathrm{DP}_{214}$. The design equation of the mapping is

$$
\left[\begin{array}{l}
\mathrm{FR}_{211} \\
\mathrm{FR}_{212} \\
\mathrm{FR}_{213} \\
\mathrm{FR}_{214}
\end{array}\right]=\left[\begin{array}{llll}
1 & 0 & 0 & 0 \\
0 & 1 & 0 & 0 \\
0 & 0 & 1 & 0 \\
0 & 0 & 0 & 1
\end{array}\right]\left[\begin{array}{l}
\mathrm{DP}_{211} \\
\mathrm{DP}_{212} \\
\mathrm{DP}_{213} \\
\mathrm{DP}_{214}
\end{array}\right] .
$$

The subfunctions of the received workpiece model, $\mathrm{FR}_{22}$, can be decomposed into the $\mathrm{ABB}$ robot input workpiece 


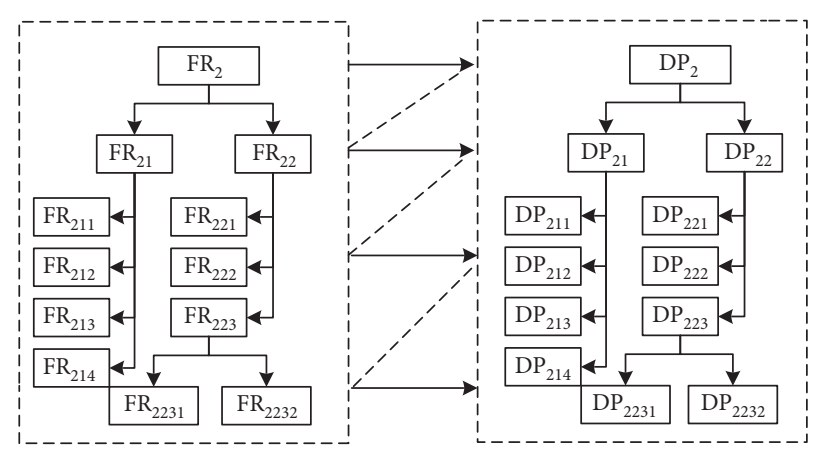

Figure 9: The zigzag mapping of $\mathrm{FR}_{2}$.

\begin{tabular}{|c|c|c|c|c|c|c|c|c|c|c|c|c|}
\hline & & \multirow{2}{*}{ Importance } & Layer 1 & \multicolumn{2}{|c|}{ Layer 2} & \multicolumn{7}{|c|}{ Layer 3} \\
\hline & & & $\mathrm{DP}_{2}$ & $\mathrm{DP}_{21}$ & $\mathrm{DP}_{22}$ & $\mathrm{DP}_{211}$ & $\mathrm{DP}_{212}$ & $\mathrm{DP}_{213}$ & $\mathrm{DP}_{214}$ & $\mathrm{DP}_{221}$ & $\mathrm{DP}_{222}$ & $\mathrm{DP}_{223}$ \\
\hline Layer 1 & $\mathrm{FR}_{2}$ & $\mu_{2}$ & & & & & & & & & & \\
\hline \multirow{2}{*}{ Layer 2} & $\mathrm{FR}_{21}$ & 4 & & 1 & 0 & & & & & & & \\
\hline & $\mathrm{FR}_{22}$ & 4 & & 1 & 1 & & & & & & & \\
\hline \multirow{7}{*}{ Layer 3} & $\mathrm{FR}_{211}$ & 3 & & & & 1 & 0 & 0 & 0 & & & \\
\hline & $\mathrm{FR}_{212}$ & 2 & & & & 0 & 1 & 0 & 0 & & & \\
\hline & $\mathrm{FR}_{213}$ & 3 & & & & 0 & 0 & 1 & 0 & & & \\
\hline & $\mathrm{FR}_{214}$ & 3 & & & & 0 & 0 & 1 & 1 & & & \\
\hline & $\mathrm{FR}_{221}$ & 2 & & & & & & & & 1 & 0 & 0 \\
\hline & $\mathrm{FR}_{222}$ & 3 & & & & & & & & 1 & 1 & 0 \\
\hline & $\mathrm{FR}_{223}$ & 4 & & & & & & & & 0 & 0 & 1 \\
\hline \multicolumn{4}{|c|}{ Importance } & 8 & 4 & 2 & 3 & 6 & 3 & 5 & 3 & 4 \\
\hline \multicolumn{4}{|c|}{ ERPN } & 64.17 & 32.08 & 3.56 & 5.35 & 13.37 & 10.03 & 13.37 & 8.03 & 24.06 \\
\hline
\end{tabular}

FIgURE 10: The risk prediction house of quality of $\mathrm{DP}_{2}$.

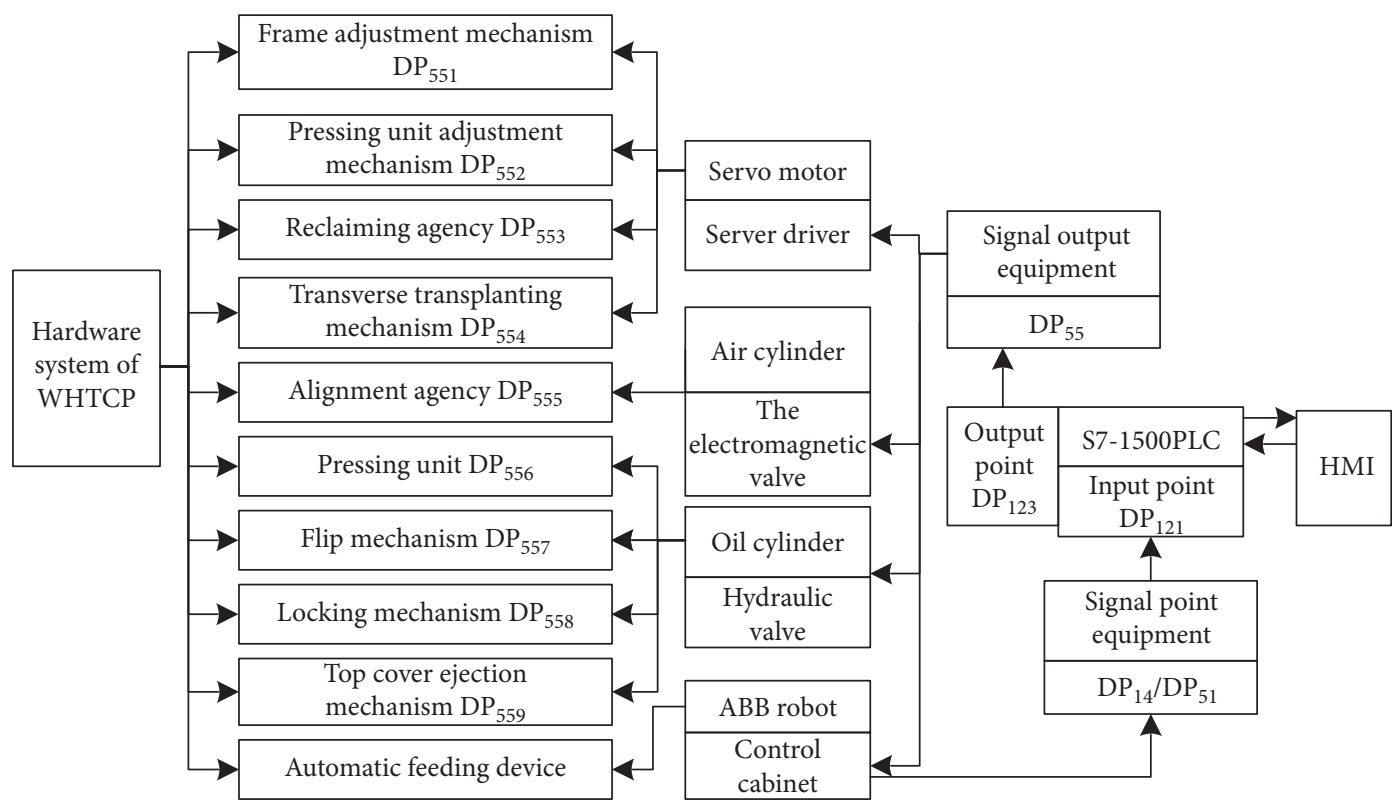

Figure 11: Hardware structure of the control service system. 


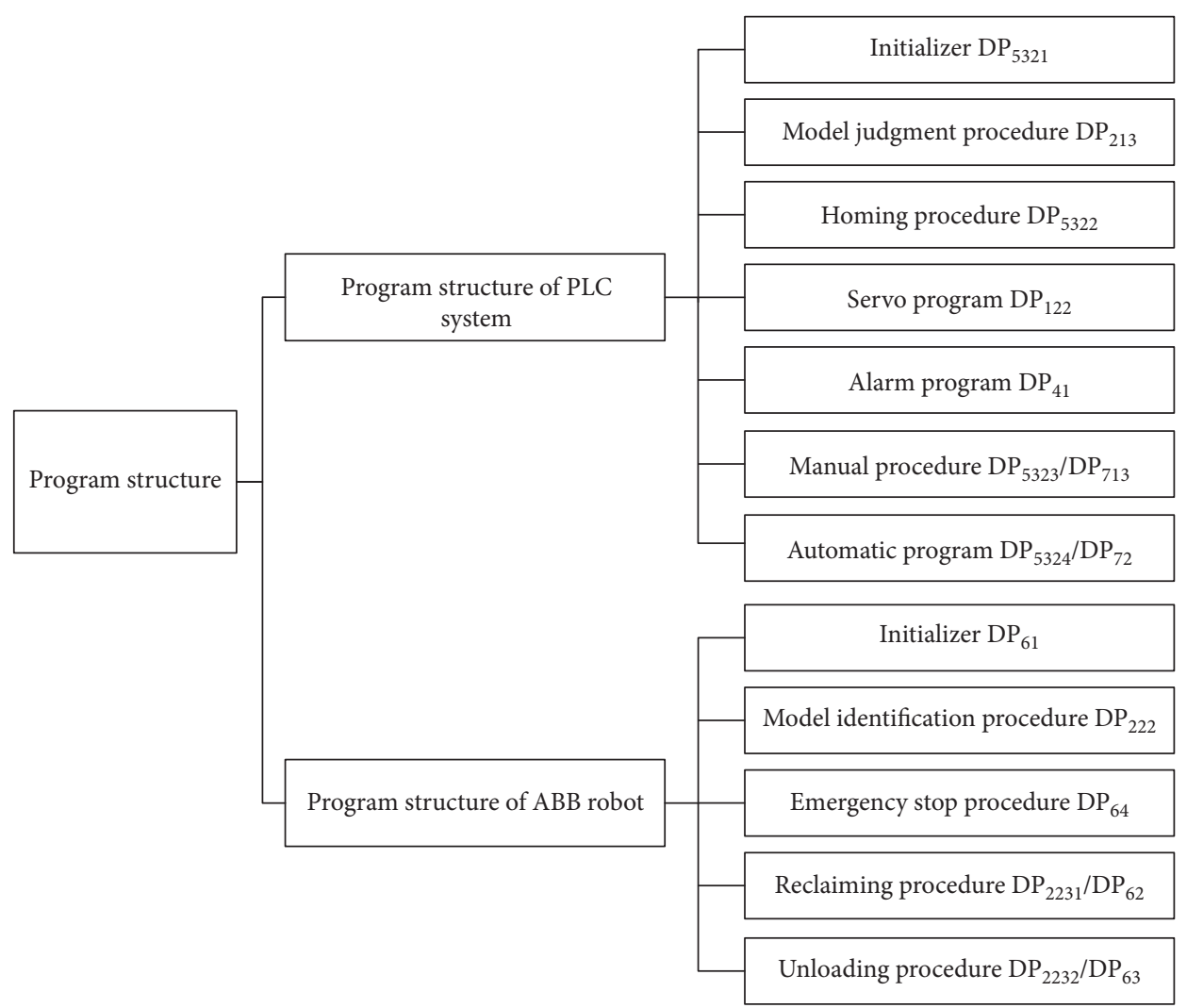

FIGURE 12: Control service system's program structure scheme.

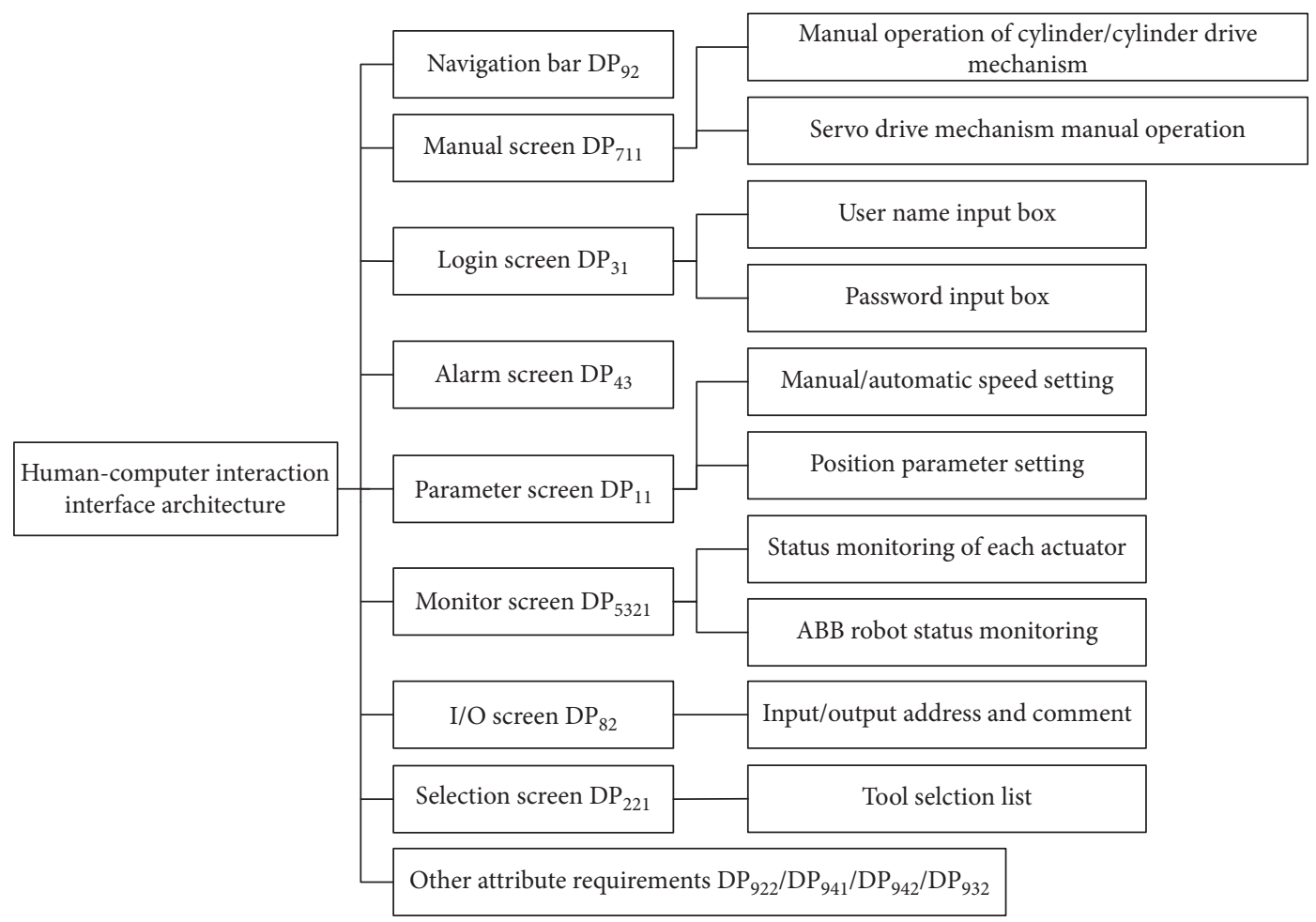

Figure 13: The human-machine interface of the control service system. 
TABLE 14: Analysis of the potential failure risk of the control service system.

\begin{tabular}{|c|c|c|c|c|c|}
\hline System & Module & Structure & $\begin{array}{c}\text { Risk } \\
\text { order }\end{array}$ & Fault description & Measures \\
\hline \multirow{5}{*}{ Hardware } & Solenoid valve & $\mathrm{DP}_{55}$ & 97.69 & $\begin{array}{l}\text { Solenoid valve does not } \\
\text { work when energized }\end{array}$ & $\begin{array}{l}\text { Select an excellent solenoid valve, with timely detection and } \\
\text { replacement }\end{array}$ \\
\hline & $\begin{array}{l}\text { Signal input } \\
\text { device }\end{array}$ & $\begin{array}{l}\mathrm{DP}_{14} \\
\mathrm{DP}_{51}\end{array}$ & $\begin{array}{l}93.13 \\
81.41\end{array}$ & Unstable signal detection & $\begin{array}{c}\text { Choose appropriate signal detection components and avoid } \\
\text { vibration }\end{array}$ \\
\hline & Servo motor & $\begin{array}{l}\mathrm{DP}_{551} \\
\mathrm{DP}_{552} \\
\mathrm{DP}_{553} \\
\mathrm{DP}_{554} \\
\mathrm{DP}_{13}\end{array}$ & $\begin{array}{l}67.84 \\
67.84 \\
67.84 \\
67.84 \\
66.23\end{array}$ & Servo drive alarm & $\begin{array}{l}\text { The installation and cable routing of the servo drive adhere } \\
\text { to strict anti-interference measures; the servo drive is } \\
\text { separately equipped with a } 24 \mathrm{~V} \text { DC power supply to ensure } \\
\text { the stability of the current in the servo system }\end{array}$ \\
\hline & $\begin{array}{l}\text { Signal input } \\
\text { element }\end{array}$ & $\begin{array}{l}\mathrm{DP}_{52} \\
\mathrm{DP}_{121}\end{array}$ & & $\begin{array}{l}\text { An abnormal or unstable } \\
\text { input signal }\end{array}$ & $\begin{array}{l}\text { Select a distributed PLC, paying attention to whether the } \\
\text { power supply voltage of the I/O terminal is normal }\end{array}$ \\
\hline & $\begin{array}{l}\text { Signal output } \\
\text { element }\end{array}$ & $\begin{array}{l}\mathrm{DP}_{54} \\
\mathrm{DP}_{123}\end{array}$ & $\begin{array}{l}56.98 \\
37.25\end{array}$ & $\begin{array}{l}\text { An abnormal or unstable } \\
\text { output signal }\end{array}$ & $\begin{array}{c}\text { Select a ground wire of sufficient diameter and add an } \\
\text { equipotential shielding plate }\end{array}$ \\
\hline \multirow{5}{*}{ Program } & $\begin{array}{l}\text { Automatic } \\
\text { program }\end{array}$ & $\mathrm{DP}_{5324}$ & 32.56 & Production cycle length & $\begin{array}{l}\text { Become familiar with the process flow and plan the system } \\
\text { action flow. }\end{array}$ \\
\hline & $\begin{array}{l}\text { Manual } \\
\text { program }\end{array}$ & $\mathrm{DP}_{5323}$ & 30.53 & $\begin{array}{l}\text { Misoperation or wrong } \\
\text { action }\end{array}$ & Set delayed action and add error-proof design \\
\hline & Alarm program & $\mathrm{DP}_{41}$ & 26.87 & Alarm is not timely & \multirow{3}{*}{$\begin{array}{l}\text { Create different alarm outputs for the different fault types } \\
\text { Refine the action; the span between each action command is } \\
\text { easily insufficiently large, so set the appropriate speed and } \\
\text { turning radius } \\
\text { Set a low speed when discharging, produce a linear motion, } \\
\text { and prevent shaking }\end{array}$} \\
\hline & $\begin{array}{l}\text { Reclaiming } \\
\text { program }\end{array}$ & $\mathrm{DP}_{62}$ & 24.80 & Poor movement & \\
\hline & $\begin{array}{c}\text { Unloading } \\
\text { program }\end{array}$ & $\mathrm{DP}_{53}$ & 24.80 & Incorrect feeding position & \\
\hline \multirow{4}{*}{ HMI } & $\begin{array}{c}\text { Action } \\
\text { command }\end{array}$ & $\mathrm{DP}_{931}$ & 13.06 & Incorrect operation & Set button delay action and error proof the design \\
\hline & $\begin{array}{l}\text { Operation } \\
\text { feedback }\end{array}$ & $\mathrm{DP}_{93}$ & 9.79 & $\begin{array}{l}\text { Operation result } \\
\text { unknown }\end{array}$ & Add operation process indicator and position indicator \\
\hline & Navigation bar & $\mathrm{DP}_{92}$ & 8.17 & $\begin{array}{l}\text { Cannot quickly switch } \\
\text { between interfaces }\end{array}$ & Set a reasonable interface display area \\
\hline & Element layout & $\mathrm{DP}_{942}$ & 6.53 & $\begin{array}{l}\text { Cannot quickly find the } \\
\text { operation button }\end{array}$ & Reasonably arrange the buttons and add notes \\
\hline
\end{tabular}

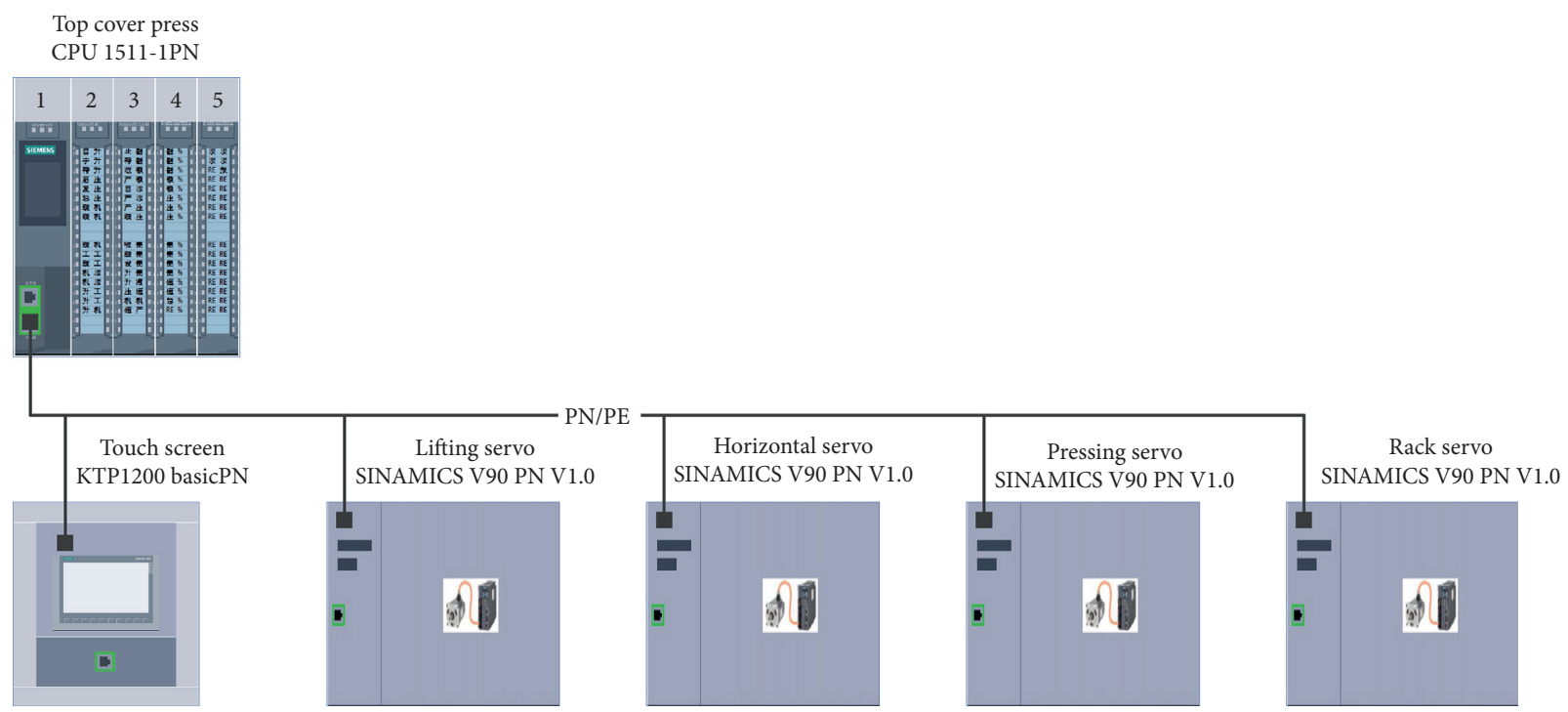

FIGURE 14: The equipment configuration network diagram of the control system of the water heater tank capping press.

information, $\mathrm{FR}_{221}$, whereas the $\mathrm{ABB}$ robot can judge the workpiece model, $\mathrm{FR}_{222}$, and executes the loading action, $\mathrm{FR}_{223}$. The working principle of model, $\mathrm{FR}_{22}$, is to receive input signals, generate control signals after the program is run, and then issue control commands. The function sequence relations are $\mathrm{FR}_{221}>\mathrm{FR}_{222}>\mathrm{FR}_{223}$. The mapping 


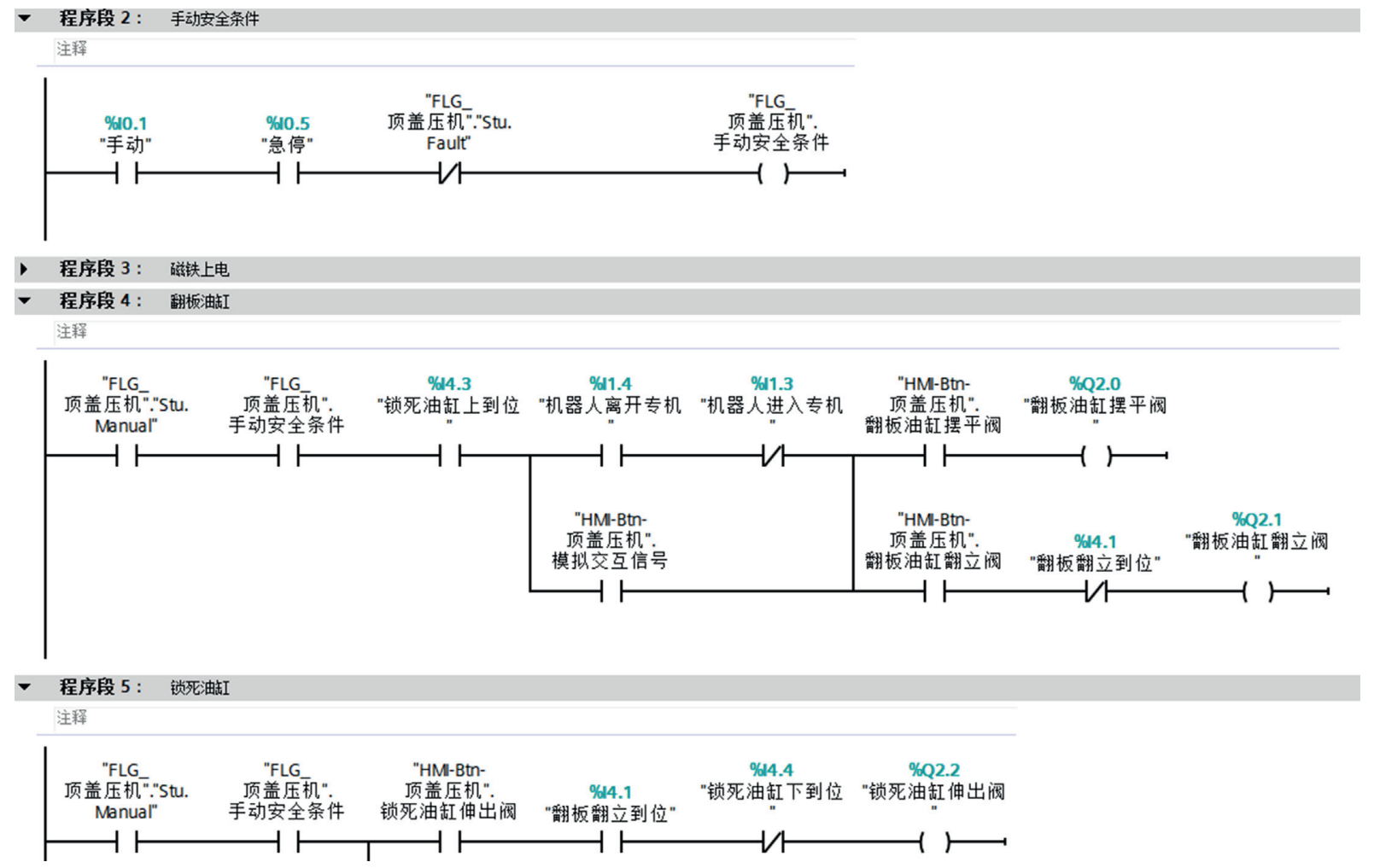

FIgURe 15: Part of the manual program of the water heater tank top press system.

structure is the $\mathrm{ABB}$ robot signal input point, $\mathrm{DP}_{221}$, the $\mathrm{ABB}$ robot model program, $\mathrm{DP}_{222}$, and feeding control program, $\mathrm{DP}_{223}$. The design equation of the mapping is then

$$
\left[\begin{array}{l}
\mathrm{FR}_{221} \\
\mathrm{FR}_{222} \\
\mathrm{FR}_{223}
\end{array}\right]=\left[\begin{array}{lll}
1 & 0 & 0 \\
0 & 1 & 0 \\
0 & 0 & 1
\end{array}\right]\left[\begin{array}{l}
\mathrm{DP}_{221} \\
\mathrm{DP}_{222} \\
\mathrm{DP}_{223}
\end{array}\right] .
$$

The zigzag mapping of the functional structure of $\mathrm{FR}_{2}$ is presented in Figure 9.

To reasonably evaluate the importance of each basic structure of $\mathrm{DP}_{2}$ and clarify the design focus of the system, the risk prediction HoQ can be illustrated according to the decomposed mapping and the zigzag mapping matrix of $\mathrm{FR}_{2}$. Furthermore, the ERPN of $\mathrm{DP}_{2}$ can be obtained, as shown in Figure 10.

As shown in Figure 10, the modules of $\mathrm{DP}_{21}, \mathrm{DP}_{223}$, and $\mathrm{DP}_{22}$ have higher risk sequence numbers. Thus, the designers should focus on analyzing possible failures and incorporate preventive measures during the design process. Similarly, other system functions, such as $\mathrm{FR}_{1}$ and $\mathrm{FR}_{3}$ to $\mathrm{FR}_{9}$ can be decomposed via mapping and solved to obtain all the basic structural modules.

\section{Construction of the Control Service System}

According to the solution for the functional structure of the control service system, the resulting basic structure can be split into a hardware system, a system program, and a human-computer interaction interface. According to the results of the risk prediction house of quality for each structural module, the structural modules are found to have a higher risk order in the hardware system, system program, or human-computer interaction interface, respectively. During the design stage, designers adopt targeted measures to resolve these potential risks and to reduce their impact on later system debugging. Figure 11 shows the hardware structural scheme of the control service system for the water tank liner top cover press system. Figure 12 shows the system's program structural scheme.

The basic structural schemes related to the humancomputer interaction interface are screened to determine those related to the human-machine interaction interface. The basic structural schemes of the human-computer interaction interface should then be combined according to the designer's knowledge of industrial human-computer interaction interfaces. Figure 13 shows the structural design of the human-computer interaction interface of the control service system.

After the hardware system's structure scheme, the system's program structure scheme, and the control service system's human-computer interaction interface structure scheme are combined, the structural modules with higher risk order numbers in every scheme must be determined (see Table 14). An analysis of these modules can determine potential failure modes and the possible consequences, and, on that basis, provide corresponding preventive measures. Potential risks can thus be resolved during the design stage. 


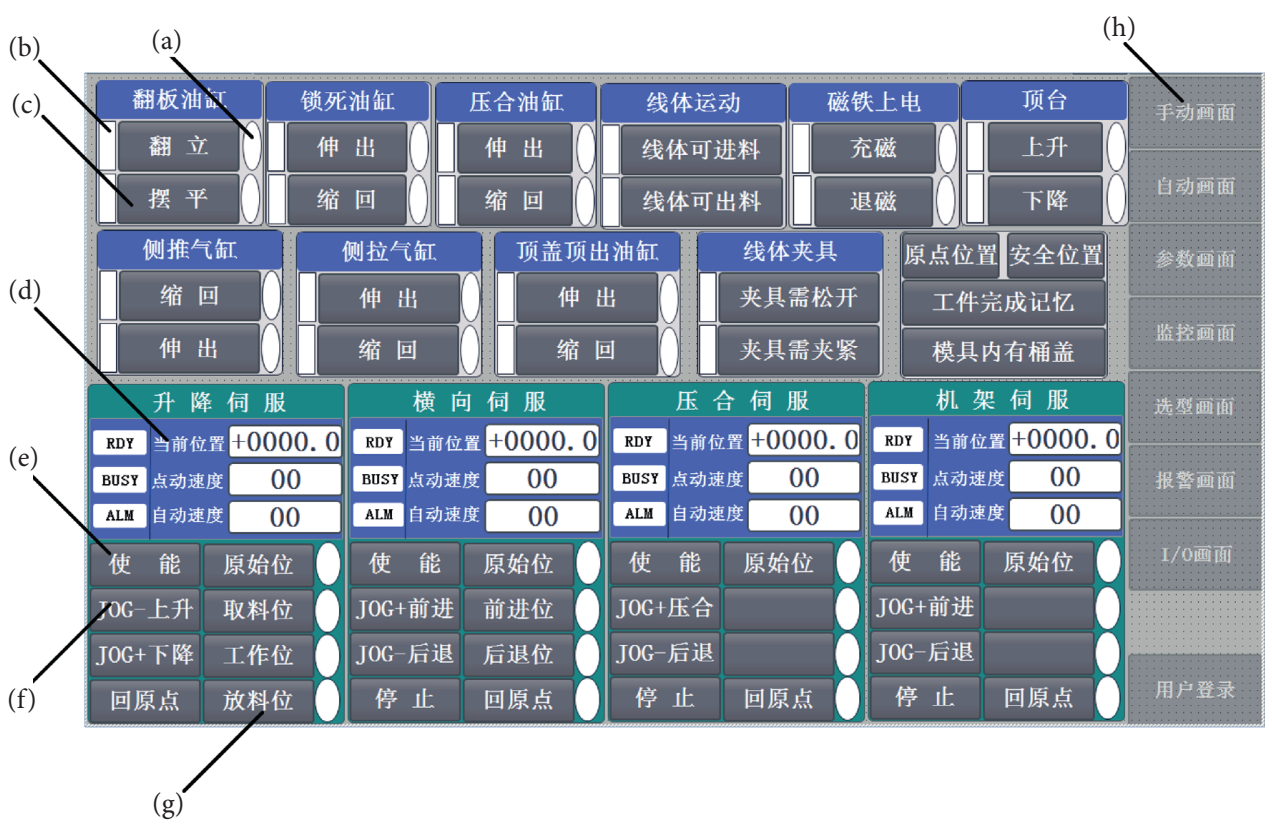

FIGURE 16: Manual operation interface of water heater tank top press system. (a) Operation feedback indication. (b) In-place instructions. (c) Operation button. (d) Servo motor monitoring. (e) Servo motor power up. (f) Servo motor inching control. (g) Step operation. (h) Navigation bar.

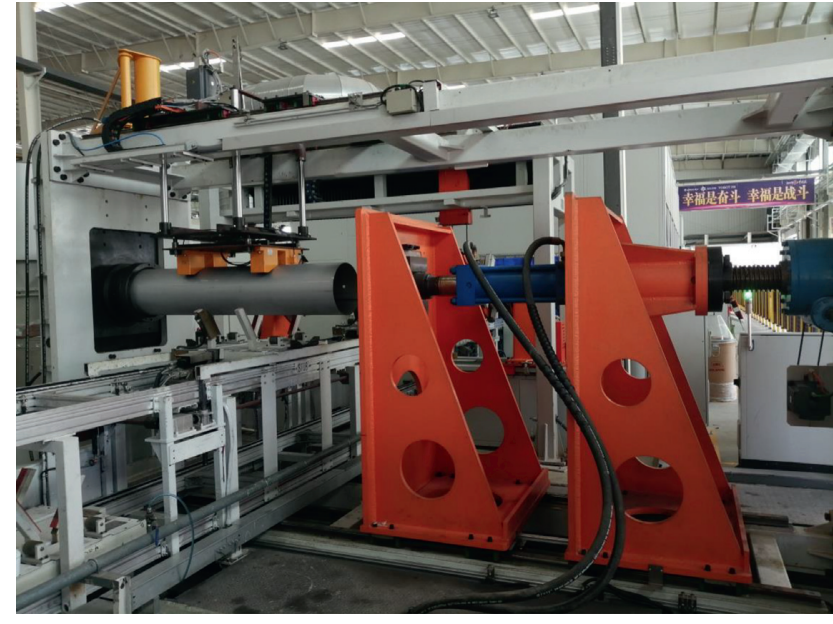

(a)

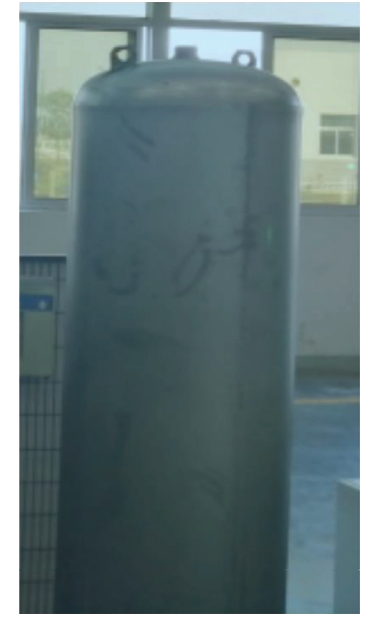

(b)

FIGURE 17: The water heater tank capping press.

\section{Conclusion}

According to the structure scheme of the control system of the water heater tank capping press, the detailed design of each structural module is carried out. In TIAPortal, the CPU1511 of S7-1500, HMI panel, and 4 servo drives form a configuration network, and Profinet industrial Ethernet is used to communicate among each part, as shown in Figure 14.

Then, according to the program structure scheme, the PLC program of the control system of the water heater tank capping press is divided into automatic program module, initialization program module, manual program module, return to the origin program module, alarm program module, and servo motor program module. Part of the manual program module is shown in Figure 15. The touch screen interface design of the control system mainly includes parameter interface, monitoring screen, selection screen, alarm screen, automatic screen, manual screen, and I/O port screen. The manual screen is shown in Figure 16. The main body of the water heater tank capping press is shown in Figure 17.

After the design of the control system is completed, the water heater tank capping press is produced and operated in the actual working environment. The water heater tank capping press works stably and satisfies the production 
demands well. It is verified that the upper design method can effectively guide the design process of the control system.

The design method preferred in this paper is based on the analysis of customer demands to ensure the accurate input of the demand domain and to complete the mapping between the demand domain and the function domain and between the function domain and the structure domain. This approach makes up for the lack of a single design method, to a certain extent. It also has the advantages of accuracy, clarity, and being a complete system. It can guide the designers to make better design decisions and evaluations during the design process more quickly and improve the design efficiency and quality of the control project. This method improves the cluster analysis of customer demands and proposes a weighted network AP clustering algorithm to determine the characteristics of customers' demands, compensating for the lack of regularization of customers' requirements in traditional $\mathrm{QFD}$ and $\mathrm{AD}$ designs. On the contrary, the method takes full advantage of QFD and AD design methods, combining the empirical design and $\mathrm{AD}$, not only benefiting from the designer's experience but also avoiding subjective influence. Finally, the effectiveness and feasibility of the proposed method are demonstrated by using the example of the design and production of the control service system for a water heater liner top cover press.

\section{Data Availability}

The data used to support the findings of this study are available from the corresponding author upon request.

\section{Conflicts of Interest}

The authors declare that they have no conflicts of interest.

\section{Acknowledgments}

This research was supported by the Zhejiang Government Science Foundation of China (Grant no. 2020C35040).

\section{References}

[1] J. Zhou, "Intelligent manufacturing-main direction of 'made in China 2025', China Mechanical Engineering, vol. 26, no. 17, pp. 2273-2284, 2015.

[2] X. Q. Xiong and Z. H. Wu, "Present situation and development trend of intelligent manufacturing in home furnishing industry," Journal of Forestry Engineering, vol. 3, no. 6, pp. 11-18, 2018.

[3] Z. H. Zhong, J. Y. Zang, J. L. Yan, Z. Z. Miao, X. Y. Yang, and $\mathrm{Y}$. $\mathrm{Gu}$, "Intelligent manufacturing promotes the comprehensive upgrading and innovative growth of China's manufacturing industry," Strategic Study of CAE, vol. 22, no. 6, pp. 136-142, 2020.

[4] Y. Zhou, J. Zang, Z. Miao, and T. Minshall, "Upgrading pathways of intelligent manufacturing in China: transitioning across technological paradigms," Engineering, vol. 5, no. 4, pp. 691-701, 2019.

[5] Y. Chu, L. Pan, K. Leng, H.-C. Fu, and A. Lam, "Research on key technologies of service quality optimizationfor industrial
IoT 5G network for intelligent manufacturing," The International Journal of Advanced Manufacturing Technology, vol. 107, no. 3-4, pp. 1071-1080, 2020.

[6] J. Wan, S. Tang, D. Li et al., "A manufacturing big data solution for active preventive maintenance," IEEE Transactions on Industrial Informatics, vol. 13, no. 4, pp. 2039-2047, 2017.

[7] L. Ren, L. Zhang, L. Wang, F. Tao, and X. Chai, "Cloud manufacturing: key characteristics and applications," International Journal of Computer Integrated Manufacturing, vol. 30, no. 6, pp. 501-515, 2017.

[8] F. Tao, W. R. Liu, J. H. Liu, and X. J. Liu, "Digital twinning and its application exploration," Computer Integrated Manufacturing Systems, vol. 24, no. 1, pp. 1-18, 2018.

[9] Y. Jiang and S. Yin, "Recent advances in key-performanceindicator oriented prognosis and diagnosis with a MATLAB toolbox: DB-KIT," IEEE Transactions on Industrial Informatics, vol. 15, no. 5, pp. 2849-2858, 2019.

[10] Y. Jiang, S. Yin, J. Dong, and O. Kaynak, "A review on soft sensors for monitoring, control and optimization of industrial processes," IEEE Sensors Journal, vol. 1, 2020.

[11] Y. Jiang, S. Yin, and O. Kaynak, "Performance supervised plant-wide process monitoring in industry 4.0: a roadmap," IEEE Open Journal of the Industrial Electronics Society, vol. 2, pp. 21-35, 2021.

[12] Y. Su and Y.-q. Yu, "Spatial agglomeration of new energy industries on the performance of regional pollution control through spatial econometric analysis," Science of the Total Environment, vol. 704, Article ID 135261, 2020.

[13] Q. Zhu, P. Jiang, M. Zheng, and D. Zhang, "Modelling machining capabilities of an industrial product service system for a machine tool," International Journal of Internet Manufacturing and Services, vol. 2, no. 2, pp. 203-213, 2010.

[14] P. Sun, C. Zhang, P. Jiang, and W. Cao, "Cutting-tool delivery method in the context of industrial product service systems," Concurrent Engineering, vol. 24, no. 2, pp. 178-190, 2016.

[15] K. Ding, P. Jiang, and M. Zheng, "Environmental and economic sustainability-aware resource service scheduling for industrial product service systems," Journal of Intelligent Manufacturing, vol. 28, no. 6, pp. 1303-1316, 2017.

[16] J. W. Leng, P. Y. Jiang, and Y. S. Ma, "Proposal of industrial product service system for oil sands mining," in Proceedings of 2015 IEEE International Conference on Mechatronics and Automation, pp. 1362-1367, Beijing, China, August 2015.

[17] D. Haeberle, S. Imran, C. van Husen, and C. Droll, "A new approach for the development of services for industrial productservice systems," Procedia CIRP, vol. 47, pp. 353-357, 2016.

[18] J. Chang, Z. Chen, X. Wang, and J. Zhang, "The determination of comprehensive importance ratings of electric vehicle's technical characteristics based on QFD under uncertain context," Computer Integrated Manufacturing Systems, vol. 26, no. 7, pp. 103-113, 2020.

[19] H. Wang, Z. Fang, D. Wang, and S. Liu, "An integrated fuzzy QFD and grey decision-making approach for supply chain collaborative quality design of large complex products," Computers \& Industrial Engineering, vol. 140, Article ID 106212, 2020.

[20] D.-I. D. Han, T. Jung, and M. C. Tom Dieck, “Translating tourist requirements into mobile $\mathrm{AR}$ application engineering through QFD," International Journal of Human-Computer Interaction, vol. 35, no. 19, pp. 1-17, 2019.

[21] S. Avikal, R. Singh, and R. Rashmi, "QFD and fuzzy Kano model based approach for classification of aesthetic attributes of SUV car profile," Journal of Intelligent Manufacturing, vol. 31, no. 2, pp. 271-284, 2018. 
[22] L. P. Chao and K. Ishii, "Project quality function deployment," International Journal of Quality \& Reliability Management, vol. 21, no. 9, pp. 938-958, 2004.

[23] S. Vinodh and G. Rathod, "Application of QFD for enabling environmentally conscious design in an Indian rotary switch manufacturing organisation," International Journal of Sustainable Engineering, vol. 3, no. 2, pp. 95-105, 2010.

[24] F. Zhang, M. Yang, and W. Liu, "Using integrated quality function deployment and theory of innovation problem solving approach for ergonomic product design," Computers \& Industrial Engineering, vol. 76, pp. 60-74, 2014.

[25] A. Aytac and V. Deniz, "Quality function deployment in education: a curriculum review," Quality \& Quantity, vol. 39, no. 4 , pp. 507-514, 2005.

[26] X. Liu, S. Huang, Z. Chen, and X. Luo, "Conceptual innovation design of seaweed planter manipulator based on TRIZ \& AD and reliability analysis," Journal of Mechanical Engineering, vol. 52, no. 5, pp. 40-46, 2016.

[27] E. C. Tamayo, Y. I. Khan, A. J. Qureshi, and M. Al-Hussein, "Conceptual design of an automated steel wall framing assembly using axiomatic design and integrated function model," Construction Robotics, vol. 3, no. 3, pp. 83-101, 2019.

[28] B. Goo, J. Lee, S. Seo, D. Chang, and H. Chung, "Design of reliability critical system using axiomatic design with FMECA," International Journal of Naval Architecture and Ocean Engineering, vol. 11, no. 1, pp. 11-21, 2017.

[29] E. Pétursson, I. N. Karlsson, O. G. Garðarsson et al., "Axiomatic design of equipment for analysis of SMA spring degradation during electronic actuation," Procedia CIRP, vol. 60, no. 2017, pp. 261-266, 2017.

[30] S. Bae, J. M. Lee, and C. N. Chu, "Axiomatic design of automotive suspension systems," CIRP Annals-Manufacturing Technology, vol. 51, no. 1, pp. 261-266, 2002.

[31] S. Lo and M. G. Helander, "Use of axiomatic design principles for analysing the complexity of human-machine systems," Theoretical Issues in Ergonomics Science, vol. 8, no. 2, pp. 47-169, 2017.

[32] M. Durmusoglu and O. Kulak, "A methodology for the design of office cells using axiomatic design principles," Omega, vol. 36, no. 4, pp. 633-652, 2008.

[33] I. Ferrer, J. Rios, and J. Ciurana, "An approach to integrate manufacturing process information in part design phases," Journal of Materials Processing Technology, vol. 209, no. 4, pp. 2085-2091, 2009.

[34] L. Y. Zhai, L. P. Khoo, and Z. W. Zhong, “Towards a QFDbased expert system: a novel extension to fuzzy QFD methodology using rough set theory," Expert Systems with Applications, vol. 37, no. 12, pp. 8888-8896, 2010.

[35] H. Cui, L. Wu, Z. He et al., "Exploring multidimensional spatiotemporal point patterns based on an improved affinity propagation algorithm," International Journal of Environmental Research and Public Health, vol. 16, no. 11, p. 1988, 2019.

[36] A. F. Moiane and Á. M. L. Machado, "Evaluation of the clustering performance of affinity propagation algorithm considering the influence of preference parameter and damping factor," Boletim de Ciências Geodésicas, vol. 24, no. 4, pp. 426-441, 2018.

[37] A. F. Moiane and Á. M. L. Machado, "Class-based affinity propagation for hyperspectral image dimensionality reduction and improvement of maximum likelihood classification accuracy," Boletim de Ciências Geodésicas, vol. 25, no. 1, Article ID e2019004, 2019.

[38] F. Zhang, "Modular configuration of service elements based on the improved K-means algorithm," Expert Systems, vol. 36, no. 5, Article ID e12344, 2018.
[39] F. Zhang, H. Ding, and N. Zhang, "Productive service demands modularization for CNC machine tools based on the improved AP clustering algorithm," Neural Computing and Applications, vol. 32, no. 6, pp. 1567-1579, 2020.

[40] P. A. Karegar, "Wireless fingerprinting indoor positioning using affinity propagation clustering methods," Wireless Networks, vol. 24, no. 8, pp. 2825-2833, 2018.

[41] Q. Tang and Z. Liao, "A semi-supervised clustering method based on an affinity propagation algorithm," Electronic Information Warfare Technology, vol. 32, no. 1, pp. 8-12, 2017.

[42] J. Jiang, Z. F. Wang, T. M. Chen, C. C. Zhu, and B. Chen, "Adaptive AP clustering algorithm and its application on intrusion detection," Journal on Communications, vol. 36, no. 11, pp. 118-126, 2015.

[43] X. H. Wang, X. P. Zhang, C. X. Zhuang, Z. N. Chen, and Z. Qin, "Automatically determining the number of affinity propagation clustering using particle swarm," in Proccedings of the 2010 5th IEEE Conference on Industrial Electronics and Applications (ICIEA), pp. 1526-1530, Taichung, Taiwan, June 2010.

[44] X. Wang, B. Zhou, Z. Wang, D. Zou, X. Chen, and Q. Zhao, "Efficiently consistent affinity propagation for 3D shapes cosegmentation," The Visual Computer, vol. 34, no. 6-8, pp. 997-1008, 2018.

[45] Z. H. Liu, B. Zhang, N. Zhu, and H. L. Tang, "Adaptive appDDoS detection method based on an improved AP algorithm," Journal of Computer Research and Development, vol. 55, no. 6, pp. 1236-1246, 2018.

[46] D. Tang, The Study of Modified Affinity Propagation Clustering and It's Application, Nanjing University of Science \& Technology, Nanjing, China, 2016.

[47] K. T. Atanassov, "Intuitionistic fuzzy sets," Fuzzy Sets and Systems, vol. 20, no. 1, pp. 87-96, 1986.

[48] A. Ermagun and D. M. Levinson, "Development and application of the network weight matrix to predict traffic flow for congested and uncongested conditions," Environment and Planning B: Urban Analytics and City Science, vol. 46, no. 9, pp. 1684-1705, 2019.

[49] J. Dong, J. Ren, and H. Lu, “A $K$-means cluster algorithm based on complex networks attribute value," Journal of Yanshan University, vol. 36, no. 4, pp. 343-347, 2012.

[50] M. Bellingeri and D. Cassi, "Robustness of weighted networks," Physica A: Statistical Mechanics and its Applications, vol. 489, pp. 47-55, 2018.

[51] L. Guo and X. Xu, Complex Networks, Shanghai Scientific \& Technical Publishers, Shanghai, China, 2006.

[52] Y. Shi and S. Han, "Modeling design research of medical service robot based on QFD and Kano model," Journal of Machine Design, vol. 34, no. 12, pp. 121-125, 2017.

[53] W. Xiong, Quality Function Deployment: Theory and Methodology, Science Press, Beijing, China, 2012.

[54] N. P. Suh, Axiomatic Design: Advances and Applications, Oxford University Press, Oxford, UK, 2004.

[55] Y. Liu, Z. Rong, and B. Dan, "Research review of axiomatic design in product design," Journal of Machine Design, vol. 30, no. 2, pp. 1-9, 2013. 